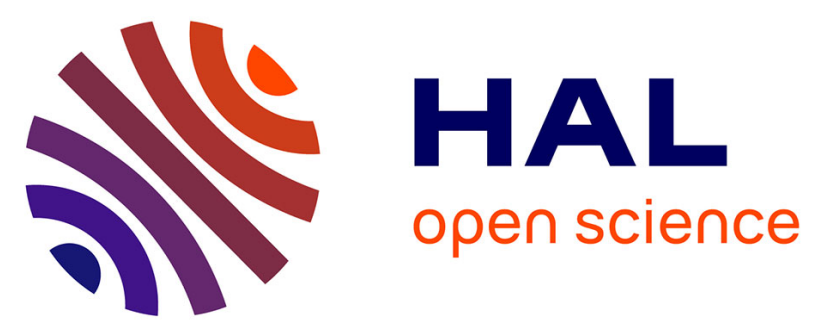

\title{
Spatial and temporal genetic structure of the planktonic Sagitta setosa (Chaetognatha) in European seas as revealed by mitochondrial and nuclear DNA markers
}

K T C A Peijnenburg, Cécile Fauvelot, J a J Breeuwer, S B J Menken

\section{- To cite this version:}

K T C A Peijnenburg, Cécile Fauvelot, J a J Breeuwer, S B J Menken. Spatial and temporal genetic structure of the planktonic Sagitta setosa (Chaetognatha) in European seas as revealed by mitochondrial and nuclear DNA markers. Molecular Ecology, 2006, 15, pp.3319 - 3338. 10.1111/j.1365294x.2006.03002.x . ird-03044198

\author{
HAL Id: ird-03044198 \\ https://hal.ird.fr/ird-03044198
}

Submitted on 7 Dec 2020

HAL is a multi-disciplinary open access archive for the deposit and dissemination of scientific research documents, whether they are published or not. The documents may come from teaching and research institutions in France or abroad, or from public or private research centers.
L'archive ouverte pluridisciplinaire HAL, est destinée au dépôt et à la diffusion de documents scientifiques de niveau recherche, publiés ou non, émanant des établissements d'enseignement et de recherche français ou étrangers, des laboratoires publics ou privés. 


\title{
Spatial and temporal genetic structure of the planktonic Sagitta setosa (Chaetognatha) in European seas as revealed by mitochondrial and nuclear DNA markers
}

\author{
K. T. C. A. PEIJNENBURG,t C. FAUVELOT, J. A. J. BREEUWER and S. B. J. MENKEN \\ Institute for Biodiversity and Ecosystem Dynamics, Faculty of Science, Universiteit van Amsterdam, PO Box 94062,1090 GB \\ Amsterdam, The Netherlands
}

\begin{abstract}
Little is known about the spatial and temporal scales at which planktonic organisms are genetically structured. A previous study of mitochondrial DNA (mtDNA) in the holoplanktonic chaetognath Sagitta setosa revealed strong phylogeographic structuring suggesting that Northeast (NE) Atlantic, Mediterranean and Black Sea populations are genetically disjunct. The present study used a higher sampling intensity and a combination of mitochondrial and four microsatellite markers to reveal population structuring between and within basins. Between basins, both marker sets indicated significant differentiation confirming earlier results that gene flow is probably absent between the respective S. setosa populations. At the within-basin scale, we found no evidence of spatial or temporal structuring within the NE Atlantic. In the Mediterranean basin, both marker sets indicated significant structuring, but only the mtDNA data indicated a sharp genetic division between Adriatic and all other Mediterranean populations. Data were inconclusive about population structuring in the Black Sea. The levels of differentiation indicated by the two marker sets differed substantially, with far less pronounced structure detected by microsatellite than mtDNA data. This study also uncovered the presence of highly divergent mitochondrial lineages that were discordant with morphology, geography and nuclear DNA. We thus propose the hypothesis that highly divergent mitochondrial lineages may be present within interbreeding $S$. setosa populations.
\end{abstract}

Keywords: chaetognaths, deep clades, European seas, marine holoplankton, microsatellites, mitochondrial DNA, population structure

Received 7 January 2006; revision received 21 April 2006; accepted 21 April 2006

\section{Introduction}

Genetic studies of open ocean species have begun to challenge the long-standing view of low species diversity and broad-scale homogeneity in the pelagic realm (Norris 2000). On the one hand, genetic studies have indicated that sibling species are far more common in marine biota than previously thought (Knowlton 1993, 2000). On the other

Correspondence: Katja T. C. A. Peijnenburg. Present address: Marine Biodiversity, Ecology and Evolution, UCD School of Biology and Environmental Science, Science and Education Research Centre (West), University College Dublin, Belfield, Dublin 4, Republic of Ireland. Fax: +353 1716 1152; E-mail: katja.peijnenburg@ucd.ie hand, broad-scale surveys of genetic variation within marine species have shown that many are more structured than would be expected based on their large population size and high potential for dispersal (Avise 2000; Grosberg \& Cunningham 2001; Hellberg et al. 2002). Genetic studies of marine holoplankton, the organisms that drift with the currents during their entire life, are particularly rare considering their abundance in the world's oceans, ecological importance and wide taxonomic representation (but see for examples of foraminifers: De Vargas et al. 1999, 2002; Darling et al. 2000; dinoflagellates: John et al. 2003; copepods: Bucklin et al. 1996, 2000; Goetze 2003, 2005; euphausiids: Bucklin et al. 1997; Zane et al. 1998, 2000; cnidarians: Schroth et al. 2002; chaetognaths: Thuesen et al. 1993; Peijnenburg et al. 2004). Yet, if we are to better understand how 
speciation takes place at open sea, particularly in holoplankton, it is necessary to examine the spatial and temporal scales at which populations of these organisms are genetically structured.

A previous study of mitochondrial DNA (mtDNA) variation in the holoplanktonic chaetognath Sagitta setosa revealed surprisingly strong phylogeographic structuring suggesting that populations in the Northeast (NE) Atlantic, Mediterranean and Black Sea are genetically disjunct (Peijnenburg et al. 2004). Based on the geological and palaeoclimatic history of the European basins and estimates of net nucleotide divergence, the authors hypothesized that $S$. setosa populations became disjunct resulting from cyclical changes in temperature and sea levels during the Pleistocene. The present study expands from our previous work and investigates more in depth, and with a hierarchical approach, the spatial and temporal structure of $S$. setosa populations.

Sagitta setosa, like all chaetognaths, is a protandrous hermaphrodite and reproduction is with internal fertilization occurring while eggs are in the ovary. Mating has rarely been observed in pelagic chaetognaths and self-fertilization is commonly observed under laboratory conditions. However, the consensus is that cross-fertilization is probably more usual in nature (Pearre 1991). Fertilized eggs are released in the sea and remain in the open water column. S. setosa occurs over continental shelf areas only. In the NE Atlantic its distribution is continuous with a southern limit at about $\sim 45^{\circ} \mathrm{N}$ where the shelf suddenly becomes narrow. Its distribution pattern in the Mediterranean Sea is more fragmented, with coastal populations in the western basin, North African waters, Ionian Sea and Adriatic Sea. The species is also abundant in the upper layers of the entire Black Sea (Furnestin 1979; Peijnenburg et al. 2004).

Considering this species' holoplanktonic lifestyle, little genetic structure within basins might be expected. However, previous work on the genetics of plankton populations suggested that distribution ranges are often not limited by the ability to disperse, but rather by the inability to maintain viable populations in areas where environmental conditions are not optimal (De Vargas et al. 1999, 2002; Norris 2000; Stewart et al. 2001; Goetze 2003, 2005; Sáez et al. 2003; Peijnenburg et al. 2004). Thus, distinct hydrographic and ecological conditions may be sufficient to reduce gene flow within seemingly continuous populations. In the North Sea, there is a single anticlockwise circulation pattern, with oceanic waters entering from the north of Scotland and through the Channel. In the Skagerrak, the North Sea water mixes with less saline water from the Baltic and is transported north along the Norwegian coast (Fig. 1A, B, Prandle 1984; Otto et al. 1990). Similarly, in the Black Sea, the main current has an anticlockwise circular motion. However, in the narrowest part of this basin, part of the waters moving from the west go north, and this sea is thus divided into two parts, each with its own gyral circulation (Fig. 1C, Zenkevitch 1963). The Mediterranean basin has sometimes been referred to as a 'sea of seas' because of its division into different subbasins, each with its own distinct characteristics, including partially enclosed gyral current systems (Fig. 1C; Pinardi \& Masetti 2000) resulting in distinct planktonic faunas (Furnestin 1979). Hence, we would expect a higher degree of genetic structuring of $S$. setosa populations within the Mediterranean than within the NE Atlantic or Black Sea basins. Earlier results from mitochondrial cytochrome oxidase II (COII) sequences have indeed suggested that this may be the case (Peijnenburg et al. 2004). However, a larger sampling intensity of individuals is needed to reveal such smallscale structuring.

The present study used a more intensive sampling of $S$. setosa from three European seas and employed both mitochondrial and microsatellite DNA markers. Furthermore, for the NE Atlantic, additional sampling localities were included to obtain a fine-scale spatial coverage of the continental shelf, which was repeated 2 years later. We used restriction fragment length polymorphism (RFLP) analysis to efficiently screen a large number of individuals for variation within the mitochondrial COII region and we developed four nuclear-encoded microsatellite loci. First, at the between-basin scale, we tested whether phylogeographic patterns were congruent between marker sets, as well as with earlier work based on a more limited sampling of $S$. setosa. Second, we examined patterns of genetic variation at within-basin scales: in the NE Atlantic we tested for small-scale spatial and temporal genetic structuring, whereas in the Mediterranean and Black Sea we tested the prediction that distinct hydrographic features limit gene flow. Finally, we compared the patterns of differentiation within basins to test the hypothesis of more genetic heterogeneity and population structuring in the Mediterranean than the NE Atlantic.

\section{Materials and methods}

\section{Sampling and DNA extraction}

We examined Sagitta setosa collected over a period of 4 years (1999-2002) from three European seas. Analyses were based on 39 samples as well as 17 samples pooled per region and year (Table 1; Fig. 1). A thorough sampling scheme was employed for the NE Atlantic with a fine-scale spatial coverage of the continental shelf region in 1999 and 2000, and an approximate repetition of this sampling scheme in 2001 (Table 1; Fig. 1A, B). To avoid sampling the same population multiple times, samples were collected over a short period and against the general circulation pattern. Additionally, for some locations (99skag1, 01skag2, 01sb1 and 01sb3) we collected multiple samples: (i) from separate hauls (denoted A and B); or (ii) as juveniles, when 


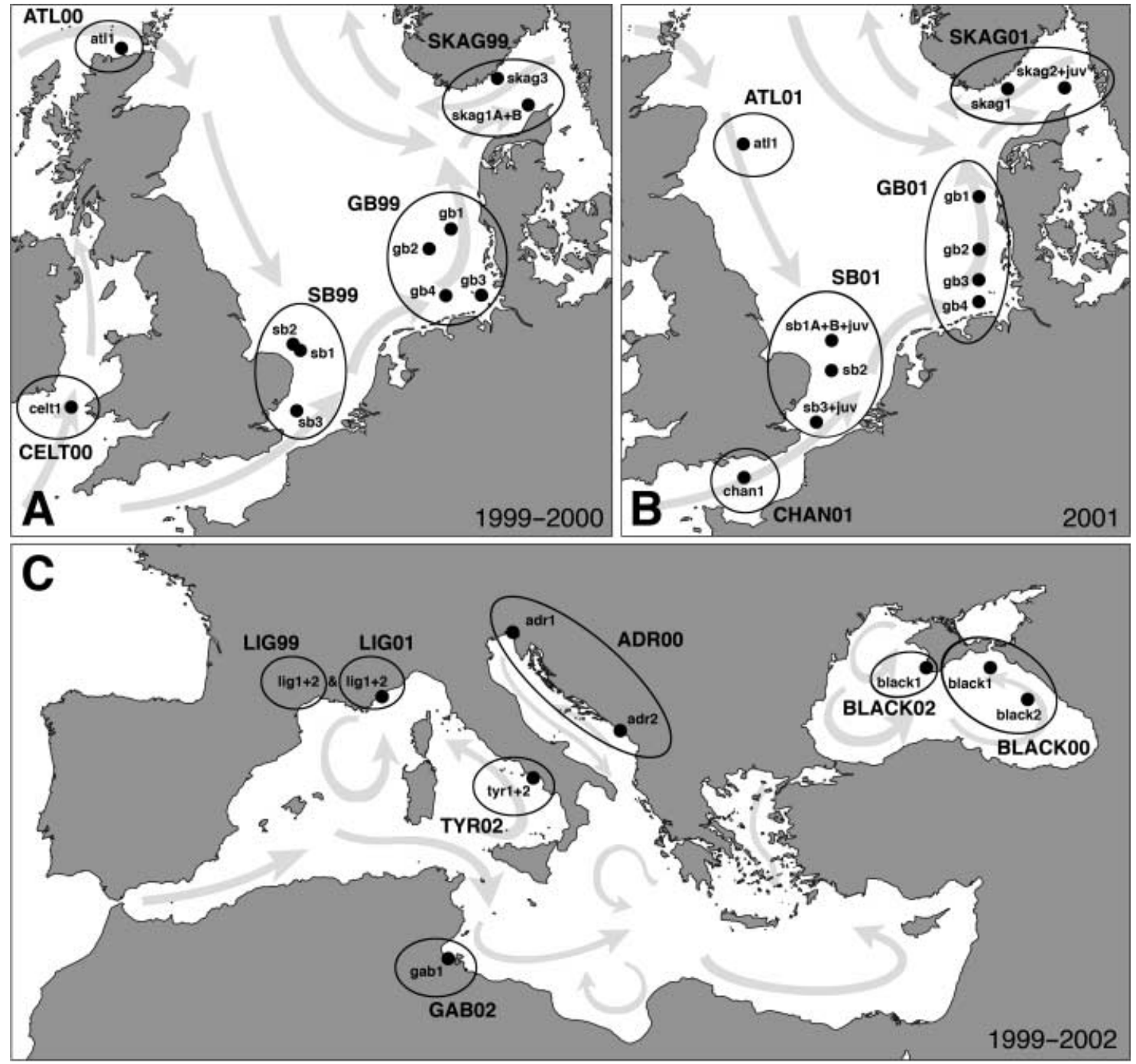

Fig. 1 Sampling locations of Sagitta setosa in the Northeast Atlantic from 1999 and 2000 (A), 2001 (B) and in the Mediterranean and Black Sea from 1999 to 2002 (C). Samples that were pooled per region and year are encircled (see also Table 1). Dominating surface currents (grey arrows) and approximate scales are indicated.

both juveniles and adults were present (denoted juv, see sample codes Table 1; Fig. 1A, B). Samples from the Mediterranean were collected from the Ligurian Sea (1999 and 2001), Tyrrhenian Sea (2002), Gulf of Gabès (2002) and Adriatic Sea (2000; Table 1; Fig. 1C). Black Sea samples were collected in 2000 (00black1 and 00black2) and 2002 (02black1). Further sampling, preservation and DNA extraction protocols were described in Peijnenburg et al. (2004).

\section{Mitochondrial DNA}

A section of the mitochondrial COII gene was screened for polymorphism using three restriction enzymes: BstEII (G GTNACC, Live Technologies), ItaI (GC NGC,
Roche Diagnostics) and HapII (C -CGG, Live Technologies). A 551-bp COII fragment was amplified using the primers and conditions described in Peijnenburg et al. (2004). Restriction digestions were carried out in $20-\mu \mathrm{L}$ total volumes containing $1 \mathrm{U}$ of a single enzyme, $4 \mu \mathrm{L}$ of the PCR (polymerase chain reaction) product and enzyme specific buffers according to manufacturer's recommendations. Resulting fragments were run on $1.5 \%$ agarose gels with TBE buffer, stained with ethidium bromide and viewed under ultra violet light. Fragment sizes were estimated against a 100-bp sizing ladder.

Composite PCR-RFLP haplotypes for each individual were defined based on restriction-site data and coded into binary $(1,0)$ format. In order to resolve restriction-site data for new haplotypes and to reveal the presence of deep 
Table 1 Sample codes, sampling information and number of individuals per sample (n). Sample codes refer to the year of sampling, geographic region, sample number, separate hauls (A or B, if applicable) and juveniles (juv, if applicable). Pooled sample codes are in capital letters and denote the region and year of sampling (for sampling locations see Fig. 1)

\begin{tabular}{|c|c|c|c|c|c|c|}
\hline Sample code & Region & Latitude & Longitude & $\begin{array}{l}\text { Sampling } \\
\text { date }\end{array}$ & $n$ & $\begin{array}{l}\text { Pooled } \\
\text { sample code }\end{array}$ \\
\hline \multicolumn{7}{|l|}{ NE Atlantic } \\
\hline 99skag1A & Skagerrak & $58^{\circ} 10.1^{\prime} \mathrm{N}$ & $08^{\circ} 44.6^{\prime} \mathrm{E}$ & 05.09.99 & 59 & SKAG99 \\
\hline 99skag1B & Skagerrak & $58^{\circ} 10.1^{\prime} \mathrm{N}$ & $08^{\circ} 44.5^{\prime} \mathrm{E}$ & 05.09 .99 & 49 & SKAG99 \\
\hline 99skag3 & Skagerrak & $57^{\circ} 42.1^{\prime} \mathrm{N}$ & $09^{\circ} 46.0^{\prime} \mathrm{E}$ & 06.09.99 & 55 & SKAG99 \\
\hline $99 \mathrm{gb} 1$ & German Bight & $55^{\circ} 23.4^{\prime} \mathrm{N}$ & $07^{\circ} 09.3^{\prime} \mathrm{E}$ & 08.09 .99 & 41 & GB99 \\
\hline $99 \mathrm{gb} 2$ & German Bight & $55^{\circ} 01.4^{\prime} \mathrm{N}$ & $06^{\circ} 24.9^{\prime} \mathrm{E}$ & 08.09 .99 & 48 & GB99 \\
\hline $99 \mathrm{gb3}$ & German Bight & $54^{\circ} 05.9^{\prime} \mathrm{N}$ & $08^{\circ} 13.3^{\prime} \mathrm{E}$ & 09.09.99 & 41 & GB99 \\
\hline $99 \mathrm{gb} 4$ & German Bight & $54^{\circ} 06.0^{\prime} \mathrm{N}$ & $06^{\circ} 58.6^{\prime} \mathrm{E}$ & 09.09 .99 & 47 & GB99 \\
\hline $99 \mathrm{sb} 1$ & Southern Bight & $52^{\circ} 59.2^{\prime} \mathrm{N}$ & $02^{\circ} 01.8^{\prime} \mathrm{E}$ & 14.09 .99 & 57 & SB99 \\
\hline 99sb2 & Southern Bight & $53^{\circ} 06.7^{\prime} \mathrm{N}$ & $01^{\circ} 48.0^{\prime} \mathrm{E}$ & 14.09 .99 & 48 & SB99 \\
\hline $99 \mathrm{sb3}$ & Southern Bight & $51^{\circ} 44.4^{\prime} \mathrm{N}$ & $01^{\circ} 54.2^{\prime} \mathrm{E}$ & 15.09 .99 & 50 & SB99 \\
\hline 00celt1 & Celtic Sea & $51^{\circ} 49.9^{\prime} \mathrm{N}$ & $05^{\circ} 46.0^{\prime} \mathrm{W}$ & 29.09 .00 & 48 & CELTO0 \\
\hline 00atl1 & Atlantic inflow & $58^{\circ} 41.2^{\prime} \mathrm{N}$ & $04^{\circ} 01.5^{\prime} \mathrm{W}$ & 16.10 .00 & 57 & ATL00 \\
\hline 01skag1 & Skagerrak & $58^{\circ} 00.0^{\prime} \mathrm{N}$ & $08^{\circ} 29.9^{\prime} \mathrm{E}$ & 24.08 .01 & 59 & SKAG01 \\
\hline 01skag2 & Skagerrak & $58^{\circ} 00.0^{\prime} \mathrm{N}$ & $10^{\circ} 24.1^{\prime} \mathrm{E}$ & 25.08 .01 & 57 & SKAG01 \\
\hline 01skag2juv & Skagerrak & $58^{\circ} 00.0^{\prime} \mathrm{N}$ & $10^{\circ} 24.1^{\prime} \mathrm{E}$ & 25.08 .01 & 25 & SKAG01 \\
\hline 01atl1 & Atlantic inflow & $57^{\circ} 00.0^{\prime} \mathrm{N}$ & $00^{\circ} 29.9^{\prime} \mathrm{W}$ & 27.08.01 & 50 & ATL01 \\
\hline 01gb1 & German Bight & $56^{\circ} 00.0^{\prime} \mathrm{N}$ & $07^{\circ} 29.9^{\prime} \mathrm{E}$ & 29.08 .01 & 55 & GB01 \\
\hline $01 \mathrm{gb} 2$ & German Bight & $55^{\circ} 00.0^{\prime} \mathrm{N}$ & $07^{\circ} 30.0^{\prime} \mathrm{E}$ & 01.09 .01 & 60 & GB01 \\
\hline $01 \mathrm{gb} 3$ & German Bight & $54^{\circ} 24.0^{\prime} \mathrm{N}$ & $07^{\circ} 30.0^{\prime} \mathrm{E}$ & 01.09.01 & 60 & GB01 \\
\hline $01 \mathrm{gb} 4$ & German Bight & $53^{\circ} 58.5^{\prime} \mathrm{N}$ & $07^{\circ} 30.0^{\prime} \mathrm{E}$ & 01.09 .01 & 57 & GB01 \\
\hline 01sb1A & Southern Bight & $53^{\circ} 12.0^{\prime} \mathrm{N}$ & $02^{\circ} 30.0^{\prime} \mathrm{E}$ & 03.09.01 & 24 & SB01 \\
\hline 01sb1B & Southern Bight & $53^{\circ} 12.0^{\prime} \mathrm{N}$ & $02^{\circ} 30.0^{\prime} \mathrm{E}$ & 03.09.01 & 19 & SB01 \\
\hline 01sb1Bjuv & Southern Bight & $53^{\circ} 12.0^{\prime} \mathrm{N}$ & $02^{\circ} 30.0^{\prime} \mathrm{E}$ & 03.09 .01 & 19 & SB01 \\
\hline $01 \mathrm{sb} 2$ & Southern Bight & $52^{\circ} 35.9^{\prime} \mathrm{N}$ & $02^{\circ} 30.1^{\prime} \mathrm{E}$ & 03.09.01 & 57 & SB01 \\
\hline 01sb3 & Southern Bight & $51^{\circ} 30.0^{\prime} \mathrm{N}$ & $01^{\circ} 59.5^{\prime} \mathrm{E}$ & 04.09 .01 & 59 & SB01 \\
\hline 01sb3juv & Southern Bight & $51^{\circ} 30.0^{\prime} \mathrm{N}$ & $01^{\circ} 59.5^{\prime} \mathrm{E}$ & 04.09 .01 & 21 & SB01 \\
\hline 01chan1 & Channel & $50^{\circ} 20.0^{\prime} \mathrm{N}$ & $00^{\circ} 30.0^{\prime} \mathrm{W}$ & 04.09.01 & 50 & CHAN01 \\
\hline \multicolumn{7}{|c|}{ Mediterranean Sea } \\
\hline 99lig1 & Ligurian Sea & $43^{\circ} 30^{\prime} \mathrm{N}$ & $07^{\circ} 12^{\prime} \mathrm{E}$ & 19.08 .99 & 44 & LIG99 \\
\hline 99lig2 & Ligurian Sea & $43^{\circ} 30^{\prime} \mathrm{N}$ & $07^{\circ} 12^{\prime} \mathrm{E}$ & 20.08 .99 & 52 & LIG99 \\
\hline 01lig1 & Ligurian Sea & $43^{\circ} 30^{\prime} \mathrm{N}$ & $07^{\circ} 12^{\prime} \mathrm{E}$ & 22.08 .01 & 35 & LIG01 \\
\hline 01lig2 & Ligurian Sea & $43^{\circ} 30^{\prime} \mathrm{N}$ & $07^{\circ} 12^{\prime} \mathrm{E}$ & 22.08 .01 & 53 & LIG01 \\
\hline 02tyr1 & Tyrrhenian Sea & $40^{\circ} 36^{\prime} \mathrm{N}$ & $14^{\circ} 30^{\prime} \mathrm{E}$ & 22.08 .02 & 41 & TYR02 \\
\hline 02tyr2 & Tyrrhenian Sea & $40^{\circ} 36^{\prime} \mathrm{N}$ & $14^{\circ} 30^{\prime} \mathrm{E}$ & 22.08 .02 & 26 & TYR02 \\
\hline 02gab1 & Gulf of Gabès & $33^{\circ} 42^{\prime} \mathrm{N}$ & $10^{\circ} 24^{\prime} \mathrm{E}$ & 19.06.02 & 69 & GAB02 \\
\hline 00adr1 & Adriatic Sea & $45^{\circ} 24^{\prime} \mathrm{N}$ & $13^{\circ} 30^{\prime} \mathrm{E}$ & 19.07.00 & 62 & ADR00 \\
\hline 00adr2 & Adriatic Sea & $42^{\circ} 18^{\prime} \mathrm{N}$ & $18^{\circ} 42^{\prime} \mathrm{E}$ & 12.07 .00 & 18 & ADR00 \\
\hline \multicolumn{7}{|l|}{ Black Sea } \\
\hline 00black1 & Black Sea & $44^{\circ} 32^{\prime} \mathrm{N}$ & $36^{\circ} 37^{\prime} \mathrm{E}$ & 14.04 .00 & 20 & BLACK00 \\
\hline 00black2 & Black Sea & $43^{\circ} 22^{\prime} \mathrm{N}$ & $38^{\circ} 24^{\prime} \mathrm{E}$ & 17.04 .00 & 17 & BLACK00 \\
\hline 02black1 & Black Sea & $44^{\circ} 30^{\prime} \mathrm{N}$ & $33^{\circ} 30^{\prime} \mathrm{E}$ & 10.08 .02 & 30 & BLACK02 \\
\hline
\end{tabular}

mitochondrial lineages, each PCR-RFLP haplotype, from different basins where possible, was sequenced (methods described in Peijnenburg et al. 2004 and Papadopoulos et al. 2005). These data were added to an existing data set of 86 unique sequences published in Peijnenburg et al. (2004), totalling 148 unique COII sequences (GenBank accession numbers AY585565-AY585650 and DQ486064-DQ486126). The Tamura-Nei model (1993) with site-specific rates was selected using Modeltest (Posada \& Crandall 1998) and used in distance calculations between sequence haplotypes. From this distance matrix, we constructed a neighbourjoining (NJ) tree in PAUP* 4.0b 10 (Swofford 1998) and assessed clade support by NJ bootstrap analysis with 1000 replicates.

After excluding all individuals belonging to deep mitochondrial clades (see Results), the number of nucleotide 
Table 2 Characteristics of four microsatellite loci developed for Sagitta setosa including primer sequences, PCR annealing temperatures ( $T_{\mathrm{a}}$ ), allele sizes, number of alleles $\left(N_{\mathrm{a}}\right)$, repeat motifs and GenBank accession numbers of the original sequenced clones. Allelic information is based on a screening of 1724 individuals (see text). Labelled primers are indicated by tIRD700 or łIRD800

\begin{tabular}{|c|c|c|c|c|c|c|}
\hline Locus & Primer sequences $\left(5^{\prime}-3^{\prime}\right)$ & $T_{\mathrm{a}}\left({ }^{\circ} \mathrm{C}\right)$ & Sizes (bp) & $N_{\mathrm{a}}$ & Repeat motif & GenBank \\
\hline Sset-1 & $\begin{array}{l}\text { F: GGGCAAGGACGAGAAGTAAA } \\
\text { R: TCGGTCCTAATGATAAGAATGG }\end{array}$ & 58 & $85-121$ & 18 & $(\mathrm{AAC})_{4}$ & DQ463218 \\
\hline Sset-2 & $\begin{array}{l}\text { F: CATGTCGGTACATCGCTGTTT† } \\
\text { R: GTGCTTCGGTTTCGCCTACT }\end{array}$ & 58 & $109-136$ & 10 & $(\mathrm{AGG})_{7}$ & DQ463219 \\
\hline Sset-3 & $\begin{array}{l}\text { F: CACTTTAGTGACACTCGTCTTGC† } \\
\text { R: GTTGGCGAAACCGGATGT }\end{array}$ & 57 & $84-279$ & 54 & $(\mathrm{CAA})_{25}$ & DQ463220 \\
\hline Sset-4 & $\begin{array}{l}\text { F: TGCGTCTCTGTCTCAGAATCC } \\
\text { R: GGACAAATTGATGGGCAAAG }\end{array}$ & 58 & $118-434$ & 89 & $(\mathrm{CTAT})_{19}$ & DQ463221 \\
\hline
\end{tabular}

substitutions per site ( $d$; Nei \& Tajima 1981; Nei \& Miller 1990) weighted by the employed enzyme classes (Nei \& Tajima 1983) between PCR-RFLP haplotypes was calculated using the program $\mathrm{D}$ in REAP (McElroy et al. 1992). REAP was also used to estimate haplotype diversity ( $h$; Nei 1987) and nucleotide diversity ( $\pi$; Nei \& Tajima 1981) within samples as well as nucleotide divergence (Nei \& Tajima 1981) between samples (program DA).

To test for population structuring, we estimated differentiation between samples as $F_{\mathrm{ST}}$ incorporating distance between haplotypes (as estimated by D in REAP) and tested for divergence from the null distribution of no differentiation by 10000 permutations, as implemented in ARLEQUIN version 2.000 (Schneider et al. 2000). For comparison, we also tested for differentiation between samples using exact tests of haplotype frequencies (not incorporating distance between haplotypes) using a Markov chain procedure (100 000 steps). For these, and all further analyses involving multiple simultaneous tests, we adjusted significance levels by applying a sequential Bonferroni correction with an initial $\alpha$ of 0.05 (Rice 1989).

Hierarchical analyses of molecular variance (AMOvA; Excoffier et al. 1992) were performed using ARLEQUIN to examine the partitioning of the total variance between various groups of samples. First, using the complete RFLP data set, we examined the partitioning of mitochondrial variation among the three basins, among samples within each basin and within samples. Second, we conducted single-level Amovas (one group of samples) to look at the partitioning of variation within basins, and among unpooled and pooled samples. Third, we carried out multilevel AMOVAs (several groups of samples) to examine the proportion of within-basin genetic variance distributed among regions (for NE Atlantic and Mediterranean Sea only) and among years (for the NE Atlantic only). Significance of $\Phi$-statistics (and associated variance components) was tested using 10000 permutations of: (i) haplotypes among samples (for single-level AMOvAs) and among groups (for multilevel AMOVAs) for $\Phi_{\mathrm{ST}}$; (ii) haplotypes among samples within groups for $\Phi_{\mathrm{SC}}$; and (iii) samples among groups for $\Phi_{\mathrm{CT}}$ (Schneider et al. 2000).

\section{Microsatellite DNA}

We used two protocols to obtain microsatellite markers for S. setosa, namely random amplified polymorphic DNA (RAPD) enrichment combined with repeat-specific PCR isolation of microsatellite arrays (PIMA method; Lunt et al. 1999) and enrichment with biotin-labelled repeat sequences (see Boneh et al. 2003). Fourteen primer pairs (seven from each protocol) were designed using the PRIMER 3 program (Rozen \& Skaletsky 1998) and tested for optimal annealing temperatures and PCR conditions. Of these, only four primer pairs resulted in reliable and interpretable fragment patterns (Table 2).

Four microsatellite loci were PCR amplified in $10 \mu \mathrm{L}$ total volumes containing $1.2 \mu \mathrm{L}$ genomic DNA, $1 \mu \mathrm{L} 10 \times$ PCR buffer (HT Biotechnology), $4 \mu \mathrm{L}$ dNTPs ( 2 mm each), $0.16 \mu \mathrm{L}$ of each of two primers $(10 \mu \mathrm{M}), 0.4$ unit of Taq polymerase (HT Biotechnology), $0.4 \mu \mathrm{L} \mathrm{MgCl}_{2}$ (25 mM) and $0.5 \mu \mathrm{L}$ bovine serum albumin (BSA, $1 \mathrm{mg} / \mathrm{mL}$ ) for loci Sset-1, Sset-2 and Sset-4, and $0.7 \mu \mathrm{L} \mathrm{MgCl}_{2}$ and $0.7 \mu \mathrm{L}$ BSA for locus Sset-3. Amplifications were carried out in a Biometra thermocycler $(\mathrm{GmBH})$ with the following profile: 3 min at $94{ }^{\circ} \mathrm{C}$, followed by 35 cycles of $25 \mathrm{~s}$ at $94{ }^{\circ} \mathrm{C}, 40 \mathrm{~s}$ at annealing temperature (Table 2), $25 \mathrm{~s}$ at $72{ }^{\circ} \mathrm{C}$ and a final extension step of $5 \mathrm{~min}$ at $72{ }^{\circ} \mathrm{C}$. Amplified PCR products were diluted 10-15 times, electrophoresed and visualized on $6.5 \%$ denaturing polyacrylamide gels in a LI-COR DNA Sequencer 4200. To ensure accuracy and consistency of scoring across gels, PCR products of four individuals with known genotypes were run for every locus in the middle and at both sides of each gel, as well as commercially available sizing standards (50-350 bp or 50-700 bp, LI-COR) for the two most variable loci. In addition, all samples with non-stepwise alleles (incongruent with the repeat motif, observed at Sset-1, Sset-3 and Sset-4) or nonamplifications (observed at Sset-3 and Sset-4) along with approximately 


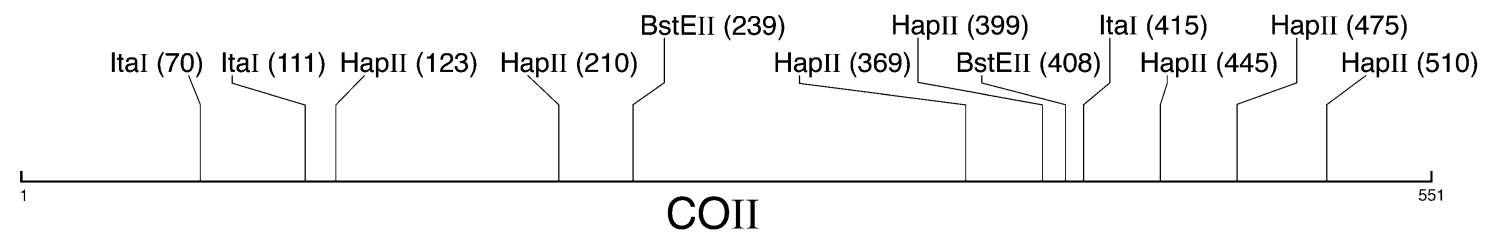

Fig. 2 Restriction map of a 551-bp fragment of the mitochondrial cytochrome oxidase II region (COII) of Sagitta setosa. Each restriction site is indicated by the enzyme by which it is recognized and the distance in base pairs (in parentheses) from the beginning of the forward primer.

$20 \%$ of genotyped individuals were re-amplified and scored, a second time to confirm repeatability.

Each allele was given a unique three-digit code based on its length in base pairs, and nonamplifying individuals were coded as missing data. Microsatellite diversity within samples was estimated as the number of alleles per locus $\left(N_{\mathrm{a}}\right)$, observed heterozygosity $\left(H_{\mathrm{O}}\right)$ and unbiased gene diversity (expected heterozygosity, $H_{E}$; Nei 1987) using FSTAT version 2.9.3.2 (Goudet 2001). Genotypes at all pairs of loci were tested for genotypic disequilibrium, and deviations from Hardy-Weinberg equilibrium (HWE) were estimated using Weir \& Cockerham's (1984) inbreeding coefficient $f$ (equivalent to Wright's $F_{\text {IS }}$ ) in GENEPOP version 3.4 (Raymond \& Rousset 1995). Locus conformance to HWE (any departure) was assessed using exact tests with significance determined by a Markov chain method, also in GENEPOP.

The presence of null alleles was detected at loci Sset3 and Sset-4 using the program MICRO-CHECKER (Van Oosterhout et al. 2004). For samples where observed genotype frequencies deviated significantly from HWE expectations, null allele frequencies were estimated using Brookfield's (1996) null allele estimator 2 (taking into account the presence of null allele homozygotes) and an alternative data set was generated in which each null allele was recoded as missing data (using MICRO-CHECKER).

Analyses to estimate differentiation between samples were carried out for both uncorrected data and data corrected for null alleles in GENEPOP. To quantify the differentiation between samples, we used the infinite allele model (IAM; Kimura \& Crow 1964) because our microsatellite loci did not conform to the strict expectations of the stepwise-mutation model (Kimura \& Ohta 1978). Thus, IAM-based estimates of $F_{\mathrm{ST}}(\theta$; following Weir \& Cockerham 1984) were calculated between all sample pairs and visualized using metric multidimensional scaling analyses (MDS; Kruskal \& Wish 1978) in xLssTAT version 7.5 (available from http://xlstat.com). To test the null hypothesis of identical allele frequency distributions across samples, an unbiased estimate of the significance was calculated as described in Raymond \& Rousset (1995).

We estimated the partitioning of total genetic variance based on allelic frequencies using AMOvA as implemented in ARLEQUIN, with the same groupings as for mtDNA analyses.
Pairwise $F_{\mathrm{ST}}$ estimates over all loci were used as distance measure for microsatellite data (Weir \& Cockerham 1984; Michalakis \& Excoffier 1996).

\section{Results}

\section{Mitochondrial DNA variability}

The COII fragment was successfully amplified and digested in 1739 individuals from three different basins. It is worth noting that a substantial proportion of the Black Sea samples (39\%) did not amplify with our COII primers. This proportion was much smaller for NE Atlantic and Mediterranean samples $(<0.01 \%$ and $0.06 \%$, respectively). Three restriction enzymes sampled $52 \mathrm{bp}$, representing 12 restriction sites that were spread along the 551-bp fragment (Fig. 2). All restriction sites were variable and resulted in 35 composite PCR-RFLP haplotypes (Table 3).

Sequence analysis of representatives of each PCR-RFLP haplotype produced a phylogenetic tree consisting of three highly divergent clades, denoted 'S. setosa', 'Sagitta sp. I' and 'Sagitta sp. II', with average maximum-likelihood distances of $14.49-25.92 \%$, as opposed to within-clade divergences of $0.20-4.42 \%$ (Fig. 3). Sagitta sp. I is identified by haplotype $\mathrm{H} 35$ and is exclusive to the Black Sea (Sagitta sp. in Peijnenburg et al. 2004). Sagitta sp. II is identified by haplotype $\mathrm{H} 34$ and was found in the NE Atlantic at very low frequencies in different sampling locations (Table 3; Fig. 3). These highly divergent clades may represent different, probably cryptic, species and are therefore not included in population genetic analyses of $S$. setosa (but see Discussion).

A total of 1724 individuals were identified with haplotypes $\mathrm{H} 1-\mathrm{H} 33$ and were considered S. setosa (Table 3). Mean haplotype diversity $( \pm S D$ ) across all samples was $0.37 \pm 0.11$ and nucleotide diversity $0.92 \pm 0.40 \%$. Both measures of diversity ( $h$ and $\pi$, respectively) were highest in Mediterranean samples $(0.50 \pm 0.04$ and $1.39 \pm 0.17 \%)$, intermediate in Black Sea samples $(0.40 \pm 0.14$ and $1.12 \pm$ $0.66 \%)$ and lowest in NE Atlantic samples (0.30 \pm 0.05 and $0.65 \pm 0.12 \%$ ). Estimates differed significantly for comparisons between Mediterranean and NE Atlantic samples only (two-tailed Student's $t$-test, $P(h)=0.0001$ and $P(\pi)=$ 0.0001). Haplotype frequencies were highly skewed for all 
Table 3 Percentage frequency of 35 composite mitochondrial PCR-RFLP DNA haplotypes (H1-H35) for 17 (pooled) samples of Sagitta setosa from the Northeast Atlantic, Mediterranean and Black Sea. The cytochrome oxidase II region was surveyed by RFLP analysis with restriction enzymes BstEII, ItaI and HapII (ones and zeros indicate the presence and absence, respectively, of restriction sites that are ordered by distance from the start of the forward primer; see Fig. 2 for restriction map). Samples from which at least one representative was sequenced for a particular haplotype (and included in the phylogenetic analysis; see Fig. 3) are underlined (see Material and methods). Haplotype diversity ( $h$ ) and nucleotide diversity $(\pi)$ for each sample are given at the bottom of the table (excluding highly divergent haplotypes H34 and H35; see text and legend Fig. 3)

\begin{tabular}{|c|c|c|c|c|c|c|c|c|c|c|c|c|c|c|c|c|c|c|c|c|}
\hline \multirow[b]{2}{*}{$\begin{array}{l}\text { Hap. } \\
\text { no. }\end{array}$} & \multirow[b]{2}{*}{$\begin{array}{l}\text { Bst } \\
\text { EII }\end{array}$} & \multirow[b]{2}{*}{ ItaI } & \multirow[b]{2}{*}{ HapII } & \multicolumn{10}{|c|}{ Northeast Atlantic } & \multicolumn{5}{|c|}{ Mediterranean Sea } & \multicolumn{2}{|c|}{ Black Sea } \\
\hline & & & & $\begin{array}{l}\text { SKAG } \\
99\end{array}$ & $\begin{array}{l}\text { GB } \\
99\end{array}$ & $\begin{array}{l}\text { SB } \\
99\end{array}$ & $\begin{array}{l}\text { CELT } \\
00\end{array}$ & $\begin{array}{l}\text { ATL } \\
00\end{array}$ & $\begin{array}{l}\text { SKAG } \\
01\end{array}$ & $\begin{array}{l}\text { ATL } \\
01\end{array}$ & $\begin{array}{l}\text { GB } \\
01\end{array}$ & $\begin{array}{l}\text { SB } \\
01\end{array}$ & $\begin{array}{l}\text { CHAN } \\
01\end{array}$ & $\begin{array}{l}\text { LIG } \\
99\end{array}$ & $\begin{array}{l}\text { LIG } \\
01\end{array}$ & $\begin{array}{l}\text { TYR } \\
02\end{array}$ & $\begin{array}{l}\text { GAB } \\
02\end{array}$ & $\begin{array}{l}\text { ADR } \\
00\end{array}$ & $\begin{array}{l}\text { BLACK } \\
00\end{array}$ & $\begin{array}{l}\text { BLACK } \\
02\end{array}$ \\
\hline & & & $n$ & 163 & 177 & 155 & 48 & 57 & 141 & 50 & 232 & 199 & 50 & 96 & 88 & 67 & 69 & 80 & 37 & 30 \\
\hline $\mathrm{H} 1$ & 00 & 011 & 0101001 & $\underline{79.8}$ & $\underline{81.4}$ & $\underline{86.5}$ & $\underline{79.2}$ & $\underline{80.7}$ & 85.1 & 86.0 & 87.1 & 87.4 & 82.0 & $\underline{1.0}$ & - & - & - & - & - & - \\
\hline $\mathrm{H} 2$ & 00 & 011 & 0101000 & $\overline{2.5}$ & $\overline{1.7}$ & $\overline{3.9}$ & $\underline{\underline{2.1}}$ & $\overline{1.8}$ & - & 2.0 & 1.7 & 0.5 & 4.0 & $\overline{-}$ & - & - & - & - & - & - \\
\hline $\mathrm{H} 3$ & 00 & 011 & 0100001 & 6.1 & 5.1 & $\overline{1.9}$ & $\underline{8.3}$ & 1.8 & 3.5 & - & 1.7 & 3.0 & 2.0 & - & - & - & - & - & - & - \\
\hline $\mathrm{H} 4$ & 00 & 011 & 0001001 & $\underline{3.7}$ & 1.1 & 2.6 & $\overline{2.1}$ & - & 0.7 & 6.0 & 0.9 & 3.0 & - & - & - & - & - & - & - & - \\
\hline H5 & 00 & 011 & 0111001 & $\overline{-}$ & - & $\underline{1.3}$ & - & - & - & - & 0.4 & - & - & - & - & - & - & - & - & - \\
\hline H6 & 00 & 011 & 1101001 & - & $\underline{0.6}$ & - & $\underline{2.1}$ & - & - & - & 0.4 & 1.0 & - & - & - & - & - & - & - & - \\
\hline $\mathrm{H} 7$ & 00 & 011 & 0100000 & - & $\overline{1.1}$ & - & $\overline{-}$ & - & - & - & - & - & - & - & - & - & - & - & - & - \\
\hline H8 & 00 & 011 & 0000000 & - & $\overline{-}$ & - & - & - & $\underline{0.7}$ & - & - & - & - & - & - & - & - & - & - & - \\
\hline H9 & 00 & 011 & 0101011 & - & 0.6 & 0.6 & - & - & $\overline{1.4}$ & - & $\underline{0.9}$ & - & 2.0 & - & - & - & - & - & - & - \\
\hline H10 & 00 & 011 & 0101101 & - & - & - & - & - & $\underline{0.7}$ & - & $\overline{-}$ & - & - & - & - & - & - & - & - & - \\
\hline H11 & 00 & 011 & 1100001 & - & - & - & - & - & $\overline{-}$ & - & $\underline{0.4}$ & - & - & - & - & - & - & - & - & - \\
\hline $\mathrm{H} 12$ & 00 & 001 & 0101001 & 1.2 & 1.7 & - & 2.1 & $\underline{3.5}$ & 2.8 & 2.0 & $\overline{1.3}$ & 1.5 & - & $\underline{63.5}$ & $\underline{70.5}$ & $\underline{70.1}$ & $\underline{68.1}$ & $\underline{17.5}$ & $\underline{67.6}$ & $\underline{60.0}$ \\
\hline H13 & 00 & 001 & 0101000 & - & $\overline{-}$ & - & - & $\underline{1.8}$ & - & - & - & - & - & $\overline{17.7}$ & $\underline{15.9}$ & $\underline{22.4}$ & $\underline{\underline{24.6}}$ & $\overline{67.5}$ & - & - \\
\hline H14 & 00 & 001 & 0100001 & - & $\underline{0.6}$ & - & - & $\overline{-}$ & - & - & - & - & - & 5.2 & $\overline{3.4}$ & $\overline{1.5}$ & $\overline{-}$ & $\overline{-}$ & $\underline{2.7}$ & $\underline{16.7}$ \\
\hline H15 & 00 & 001 & 0001001 & - & $\overline{-}$ & - & - & - & - & - & - & 0.5 & - & 1.0 & $\underline{1.1}$ & 1.5 & - & - & $\overline{2.7}$ & $\overline{-}$ \\
\hline H16 & 00 & 001 & 0111001 & - & - & - & - & - & - & - & - & - & - & $\underline{2.1}$ & - & 1.5 & - & - & 8.1 & - \\
\hline H17 & 00 & 001 & 0001000 & - & - & - & - & - & - & - & - & - & - & $\underline{2.1}$ & 1.1 & - & 1.4 & 3.8 & - & - \\
\hline H18 & 00 & 001 & 0100000 & - & - & - & - & - & - & - & - & - & - & $\overline{2.1}$ & $\underline{3.4}$ & - & 1.4 & 2.5 & - & 3.3 \\
\hline H19 & 00 & 001 & 1101000 & - & - & - & - & - & - & - & - & - & - & - & - & - & - & $\underline{1.3}$ & - & - \\
\hline
\end{tabular}


Table 3 Continued

\begin{tabular}{|c|c|c|c|c|c|c|c|c|c|c|c|c|c|c|c|c|c|c|c|c|}
\hline \multirow[b]{2}{*}{$\begin{array}{l}\text { Hap. } \\
\text { no. }\end{array}$} & \multirow[b]{2}{*}{$\begin{array}{l}\text { Bst } \\
\text { EII }\end{array}$} & \multirow[b]{2}{*}{ ItaI } & \multirow[b]{2}{*}{ HapII } & \multicolumn{10}{|c|}{ Northeast Atlantic } & \multicolumn{5}{|c|}{ Mediterranean Sea } & \multicolumn{2}{|c|}{ Black Sea } \\
\hline & & & & $\begin{array}{l}\text { SKAG } \\
99\end{array}$ & $\begin{array}{l}\text { GB } \\
99\end{array}$ & $\begin{array}{l}\text { SB } \\
99\end{array}$ & $\begin{array}{l}\text { CELT } \\
00\end{array}$ & $\begin{array}{l}\text { ATL } \\
00\end{array}$ & $\begin{array}{l}\text { SKAG } \\
01\end{array}$ & $\begin{array}{l}\text { ATL } \\
01\end{array}$ & $\begin{array}{l}\text { GB } \\
01\end{array}$ & $\begin{array}{l}\text { SB } \\
01\end{array}$ & $\begin{array}{l}\text { CHAN } \\
01\end{array}$ & $\begin{array}{l}\text { LIG } \\
99\end{array}$ & $\begin{array}{l}\text { LIG } \\
01\end{array}$ & $\begin{array}{l}\text { TYR } \\
02\end{array}$ & $\begin{array}{l}\text { GAB } \\
02\end{array}$ & $\begin{array}{l}\text { ADR } \\
00\end{array}$ & $\begin{array}{l}\text { BLACK } \\
00\end{array}$ & $\begin{array}{l}\text { BLACK } \\
02\end{array}$ \\
\hline $\mathrm{H} 20$ & 00 & 001 & 0111000 & - & - & - & - & - & - & - & - & - & - & - & - & - & - & $\underline{3.8}$ & - & - \\
\hline $\mathrm{H} 21$ & 00 & 111 & 0101001 & 0.6 & 0.6 & - & - & - & 0.7 & 2.0 & 0.4 & $\underline{0.5}$ & 2.0 & - & - & - & - & - & - & - \\
\hline $\mathrm{H} 22$ & 00 & 101 & 0101001 & - & - & - & - & - & - & - & - & $\overline{-}$ & - & 1.0 & - & - & $\underline{1.4}$ & - & - & - \\
\hline $\mathrm{H} 23$ & 00 & 101 & 0101000 & - & - & - & - & - & - & - & - & - & - & - & - & - & $\overline{-}$ & $\underline{1.3}$ & - & - \\
\hline $\mathrm{H} 24$ & 00 & 101 & 0111001 & - & - & - & - & - & - & - & - & - & - & - & $\underline{1.1}$ & - & - & $\overline{-}$ & - & - \\
\hline $\mathrm{H} 25$ & 00 & 010 & 0101001 & $\underline{0.6}$ & - & - & - & - & - & - & - & 0.5 & - & - & - & - & - & - & - & - \\
\hline $\mathrm{H} 26$ & 00 & 010 & 0101011 & - & - & - & - & - & - & - & $\underline{0.4}$ & - & - & - & - & - & - & - & - & - \\
\hline $\mathrm{H} 27$ & 10 & 011 & 0101000 & - & - & $\underline{0.6}$ & - & - & - & - & $\overline{0.4}$ & - & - & - & - & - & - & - & - & - \\
\hline $\mathrm{H} 28$ & 10 & 011 & 0001001 & $\underline{0.6}$ & - & $\overline{-}$ & - & - & - & - & - & - & - & - & - & - & - & - & - & - \\
\hline $\mathrm{H} 29$ & 10 & 101 & 0101001 & $\overline{-}$ & - & - & - & - & - & - & - & - & - & - & - & $\underline{1.5}$ & - & - & - & - \\
\hline H30 & 01 & 011 & 0101001 & - & 1.1 & $\underline{0.6}$ & - & - & - & - & - & - & - & - & - & $\overline{-}$ & - & - & - & - \\
\hline H31 & 10 & 011 & 0101001 & $\underline{3.7}$ & 4.0 & $\overline{1.3}$ & 4.2 & 5.3 & 4.3 & - & 3.0 & 1.5 & 8.0 & - & - & - & - & - & - & $\underline{6.7}$ \\
\hline H32 & 10 & 001 & 0101001 & $\underline{0.6}$ & $\underline{0.6}$ & - & - & $\underline{3.5}$ & - & $\underline{2.0}$ & - & $\underline{0.5}$ & - & $\underline{4.2}$ & $\underline{1.1}$ & - & 1.4 & $\underline{1.3}$ & - & - \\
\hline H33 & 10 & 001 & 0101000 & $\overline{-}$ & $\overline{-}$ & $\underline{0.6}$ & - & $\overline{-}$ & - & $\overline{-}$ & - & $\overline{-}$ & - & $\overline{-}$ & $\underline{2.3}$ & $\underline{1.5}$ & 1.4 & $\overline{1.3}$ & - & - \\
\hline H34 & 00 & 101 & 0011000 & $\underline{0.6}$ & - & $\overline{-}$ & - & $\underline{1.8}$ & - & - & $\underline{0.9}$ & - & - & - & $\overline{-}$ & $\overline{-}$ & - & - & - & - \\
\hline H35 & 00 & 101 & 0000000 & $\overline{-}$ & - & - & - & $\overline{-}$ & - & - & $\overline{-}$ & - & - & - & - & - & - & - & $\underline{18.9}$ & $\underline{13.3}$ \\
\hline \multirow{3}{*}{\multicolumn{3}{|c|}{ Excl. H34 and H35: }} & $n$ & 162 & 177 & 155 & 48 & 56 & 141 & 50 & 230 & 199 & 50 & 96 & 88 & 67 & 69 & 80 & 30 & 26 \\
\hline & & & $h$ & 0.35 & 0.33 & 0.25 & 0.37 & 0.32 & 0.27 & 0.26 & 0.23 & 0.23 & 0.32 & 0.56 & 0.48 & 0.46 & 0.48 & 0.52 & 0.30 & 0.50 \\
\hline & & & $\pi$ & 0.76 & 0.77 & 0.56 & 0.75 & 0.83 & 0.61 & 0.58 & 0.48 & 0.50 & 0.63 & 1.61 & 1.48 & 1.19 & 1.27 & 1.40 & 0.65 & 1.59 \\
\hline
\end{tabular}

$n$, number of individuals screened; $h$, haplotype diversity; $\pi$, nucleotide diversity in percentages. For sample codes see Table 1. 


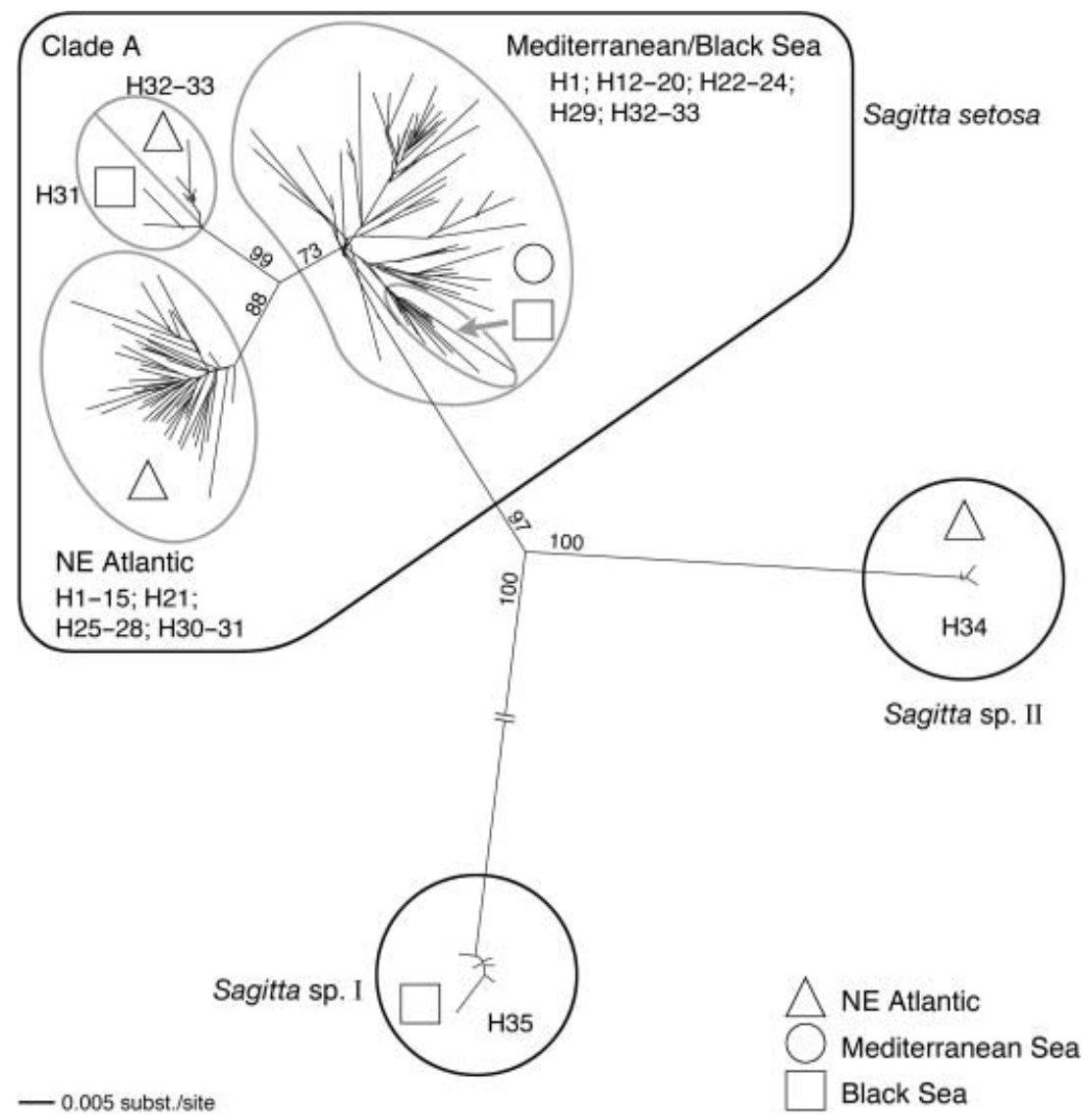

Fig. 3 Unrooted neighbour-joining tree of 148 cytochrome oxidase II sequence haplotypes (GenBank accession numbers AY585565AY585650 and DQ486064-DQ486126) sampled in morphologically identified samples of Sagitta setosa from the Northeast Atlantic, Mediterranean and Black Sea. Supported groupings are encircled and bootstrap support is indicated on major branches. PCR-RFLP haplotypes (H1-H35, see Table 3) present within a clade as well as their geographic origin are indicated (see legend). Two highly divergent clades, denoted Sagitta sp. I (PCRRFLP haplotype H35) and Sagitta sp. II (PCR-RFLP haplotype H34) may represent different (cryptic) species and were therefore not included in population genetic analyses (see text). samples (Table 3). Frequency distributions for NE Atlantic samples were most skewed with a single common haplotype at very high frequencies (79.2-87.4\%) and 23 haplotypes at very low frequencies $(0.4-8.3 \%)$. Frequency distributions of Mediterranean samples were least skewed with two relatively common haplotypes (H12: 17.5-70.5\% and H13: $15.9-67.5 \%)$ and 14 rare haplotypes $(1.0-5.2 \%)$.

\section{Microsatellite variability}

The same individuals that were used in mtDNA analyses were screened for microsatellite variability. It is notable that individuals belonging to deep mitochondrial clades (Sagitta sp. I and Sagitta sp. II) and those that failed to amplify with the mitochondrial primers (mostly Black Sea samples) successfully amplified with all microsatellite primer pairs and produced common allelic patterns. This suggests that bad DNA quality is not a likely cause of the mitochondrial amplification failures. Nevertheless, microsatellite analyses of population structure only included the 1724 individuals that were identified by mitochondrial haplotypes H1-H33 (considered S. setosa).

The four microsatellite loci varied widely in number of alleles $(2-42$, mean $=16.5)$ and expected heterozygosities
$(0.015-0.956$, mean $=0.660)$ across samples $($ Table 4$)$. Non-stepwise alleles were observed at low frequencies at Sset-1 (0.64\%), Sset-3 (1.61\%) and Sset-4 (2.65\%). Tests of genotypic disequilibrium within samples between the four loci indicated no significant association of alleles (all $P>0.33$ ), confirming that all loci can be treated as independent markers. Levels of genetic variability over all loci were similar across samples between the three basins, with no evidence against the null hypothesis of equal mean values of observed heterozygosities (two-tailed Student's $t$-test, $P=0.126-0.437$ ).

Heterozygote deficiencies were observed at Sset-3 and Sset- 4 for all samples ( $F_{\text {IS }}$ values ranged from 0.155 to 0.554 for Sset-3 and 0.100-0.435 for Sset-4) and were significant except for BLACK00 at Sset-3, and CELT00 and ATL01 at Sset-4 (Table 4). By contrast, all samples conformed to HWE expectations at Sset-1 $\left(F_{\text {IS }}=-0.047-0.182\right)$ and Sset-2 $\left(F_{\text {IS }}=-0.105-0.187\right)$. Null alleles were the most likely cause of departures from HWE and estimated null allele frequencies $(r)$ per sample were high $(0.108-0.411$ for Sset-3 and 0.160-0.311 for Sset-4; Table 4). Results for the unpooled data set of 39 samples were similar but are not shown here because of space limitations. Allele frequencies at each locus for each sample from original and adjusted data sets are available upon request. 
Table 4 Levels of genetic variability at four microsatellite loci for 17 (pooled) samples of Sagitta setosa. $n$, sample size; $N_{a^{\prime}}$, number of alleles; $H_{\mathrm{E}}$, expected heterozygosity; $H_{\mathrm{O}}$, observed heterozygosity; and $r$, null allele frequency as estimated by Brookfield's (1996) estimator 2 using MICRO-CHECKER. Significant deviations from Hardy-Weinberg equilibrium are in bold (null allele frequencies are only listed if a significant deviation was observed)

\begin{tabular}{|c|c|c|c|c|c|c|c|c|c|c|c|c|c|c|c|c|c|}
\hline & \multicolumn{10}{|c|}{ NE Atlantic } & \multicolumn{5}{|c|}{ Mediterranean Sea } & \multicolumn{2}{|l|}{ Black Sea } \\
\hline & SKAG99 & GB99 & SB99 & CELT00 & ATL00 & SKAG01 & ATL01 & GB01 & SB01 & CHAN01 & LIG99 & LIG01 & TYR02 & GAB02 & ADR00 & BLACK00 & BLACK02 \\
\hline \multicolumn{18}{|c|}{ Locus } \\
\hline \multicolumn{18}{|c|}{ Sset-1 } \\
\hline$n$ & 162 & 177 & 155 & 48 & 56 & 141 & 50 & 230 & 199 & 50 & 96 & 88 & 66 & 68 & 78 & 30 & 26 \\
\hline$N_{\mathrm{a}}$ & 8 & 6 & 4 & 5 & 2 & 4 & 2 & 6 & 6 & 2 & 5 & 3 & 4 & 2 & 4 & 4 & 3 \\
\hline$H_{\mathrm{E}}$ & 0.113 & 0.083 & 0.069 & 0.102 & 0.035 & 0.076 & 0.020 & 0.085 & 0.074 & 0.040 & 0.111 & 0.045 & 0.060 & 0.015 & 0.038 & 0.159 & 0.147 \\
\hline$H_{\mathrm{O}}$ & 0.093 & 0.085 & 0.058 & 0.104 & 0.036 & 0.078 & 0.020 & 0.078 & 0.065 & 0.040 & 0.104 & 0.045 & 0.061 & 0.015 & 0.038 & 0.167 & 0.154 \\
\hline \multicolumn{18}{|c|}{ Sset-2 } \\
\hline$n$ & 162 & 177 & 155 & 48 & 56 & 141 & 50 & 230 & 199 & 50 & 96 & 88 & 67 & 69 & 80 & 30 & 26 \\
\hline$N_{\mathrm{a}}$ & 8 & 6 & 8 & 6 & 7 & 7 & 6 & 7 & 8 & 6 & 7 & 8 & 6 & 7 & 10 & 9 & 6 \\
\hline$H_{\mathrm{E}}^{\mathrm{a}}$ & 0.673 & 0.677 & 0.668 & 0.674 & 0.713 & 0.665 & 0.584 & 0.683 & 0.666 & 0.663 & 0.652 & 0.667 & 0.710 & 0.714 & 0.668 & 0.803 & 0.765 \\
\hline$H_{\mathrm{O}}$ & 0.660 & 0.718 & 0.548 & 0.688 & 0.714 & 0.674 & 0.520 & 0.696 & 0.693 & 0.540 & 0.677 & 0.693 & 0.612 & 0.667 & 0.738 & 0.867 & 0.692 \\
\hline \multicolumn{18}{|c|}{ Sset-3 } \\
\hline$n$ & 150 & 163 & 140 & 45 & 55 & 131 & 49 & 208 & 186 & 44 & 92 & 81 & 63 & 61 & 78 & 30 & 26 \\
\hline$N_{\mathrm{a}}$ & 35 & 26 & 31 & 22 & 23 & 30 & 25 & 32 & 28 & 23 & 26 & 29 & 24 & 24 & 24 & 21 & 16 \\
\hline$H_{\mathrm{E}}^{\mathrm{a}}$ & 0.943 & 0.941 & 0.941 & 0.938 & 0.944 & 0.940 & 0.948 & 0.939 & 0.941 & 0.910 & 0.947 & 0.947 & 0.947 & 0.943 & 0.944 & 0.905 & 0.916 \\
\hline$H_{\mathrm{O}}$ & 0.467 & 0.442 & 0.486 & 0.444 & 0.509 & 0.519 & 0.429 & 0.500 & 0.425 & 0.455 & 0.424 & 0.506 & 0.540 & 0.426 & 0.641 & 0.767 & 0.692 \\
\hline$r$ & 0.346 & 0.363 & 0.364 & 0.338 & 0.248 & 0.317 & 0.293 & 0.356 & 0.354 & 0.394 & 0.325 & 0.335 & 0.294 & 0.411 & 0.195 & - & 0.108 \\
\hline \multicolumn{18}{|c|}{ Sset-4 } \\
\hline$n$ & 157 & 172 & 148 & 48 & 53 & 139 & 49 & 220 & 195 & 48 & 90 & 83 & 64 & 64 & 77 & 29 & 25 \\
\hline$N_{\mathrm{a}}$ & 31 & 35 & 32 & 27 & 23 & 35 & 25 & 40 & 42 & 26 & 30 & 29 & 26 & 22 & 26 & 21 & 22 \\
\hline$H_{\mathrm{E}}^{\mathrm{a}}$ & 0.951 & 0.948 & 0.954 & 0.948 & 0.933 & 0.956 & 0.944 & 0.950 & 0.955 & 0.950 & 0.938 & 0.920 & 0.923 & 0.937 & 0.920 & 0.948 & 0.953 \\
\hline$H_{\mathrm{O}}^{\mathrm{L}}$ & 0.739 & 0.610 & 0.628 & 0.854 & 0.679 & 0.633 & 0.796 & 0.677 & 0.677 & 0.667 & 0.644 & 0.554 & 0.563 & 0.531 & 0.597 & 0.655 & 0.640 \\
\hline$r$ & 0.160 & 0.218 & 0.236 & - & 0.215 & 0.188 & - & 0.209 & 0.175 & 0.207 & 0.246 & 0.275 & 0.255 & 0.311 & 0.227 & 0.199 & 0.215 \\
\hline \multicolumn{18}{|c|}{ Mean } \\
\hline$N_{\mathrm{a}}$ & 20.5 & 18.3 & 18.8 & 15.0 & 13.8 & 19.0 & 14.5 & 21.3 & 21.0 & 14.3 & 17.0 & 17.3 & 15.0 & 13.8 & 16.0 & 13.8 & 11.8 \\
\hline$H_{\mathrm{E}}^{\mathrm{a}}$ & 0.670 & 0.662 & 0.658 & 0.665 & 0.656 & 0.659 & 0.624 & 0.664 & 0.659 & 0.641 & 0.662 & 0.645 & 0.660 & 0.652 & 0.643 & 0.704 & 0.695 \\
\hline$H_{\mathrm{O}}$ & 0.490 & 0.464 & 0.430 & 0.523 & 0.485 & 0.476 & 0.441 & 0.488 & 0.465 & 0.425 & 0.462 & 0.450 & 0.444 & 0.410 & 0.504 & 0.614 & 0.545 \\
\hline
\end{tabular}




\section{Population structure of S. setosa}

Mitochondrial DNA. Phylogenetic analysis of COII sequences indicated strong phylogeographic structuring within the S. setosa clade (Fig. 3). This clade consisted of three subclades of which two were consistent with geography, and one was not. Of the two clades that were consistent with geography, one clade consisted entirely of NE Atlantic haplotypes and the other clade consisted of Mediterranean and Black Sea haplotypes. The Mediterranean/ Black Sea clade could be further subdivided and contained a monophyletic group representing all Black Sea haplotypes (see also Peijnenburg et al. 2004). The third clade, not consistent with geography, was denoted 'Clade $\mathrm{A}^{\prime}$ and included NE Atlantic as well as Black Sea haplotypes. Clade A appeared intermediate between the NE Atlantic and Mediterranean/Black Sea clades, with average ( \pm SD) maximum-likelihood divergences from these clades of $4.94 \pm 0.54 \%$ and $5.14 \pm 0.71 \%$, respectively. One representative of Clade A was found in an earlier study (individual N3-3 in Peijnenburg et al. 2004) and was identified by RFLP haplotype H32. All other individuals belonging to this clade were identified by haplotypes $\mathrm{H} 32$ or H33 for NE Atlantic samples, and by H31 for Black Sea samples, and were sequenced to confirm this. Using this screening technique, 7 out of 1268 individuals from the NE Atlantic and 2 out of 56 individuals from the Black Sea were identified as Clade A. There was some bootstrap support for the grouping of NE Atlantic haplotypes H32 and H33 (59\%) and Black Sea haplotypes H31 (69\%) into two separate clades within Clade A (Fig. 3).

Congruent with sequence data, frequency distributions of RFLP haplotypes showed a distinct division of samples into two major groups: a NE Atlantic group with $\mathrm{H} 1$ as most common haplotype and a Mediterranean/Black Sea group with $\mathrm{H} 12$ or $\mathrm{H} 13$ as most common haplotype (Table 3). Not surprisingly, differentiation between the three basins was highly significant (global exact test, $P<0.001) . F_{\mathrm{ST}}$ estimates between basins were 0.71 (NE Atlantic-Mediterranean), 0.73 (NE Atlantic-Black Sea) and 0.15 (Mediterranean-Black Sea), and all differed significantly from zero (permutation tests, all $P<0.001$ ). Net nucleotide divergence between basins amounted to $2.15 \%$ (NE Atlantic-Mediterranean), 1.75\% (NE Atlantic-Black Sea) and $0.29 \%$ (Mediterranean-Black Sea).

Within the NE Atlantic, no evidence of geographic or temporal structuring of samples was observed (global exact test for unpooled and pooled data sets, $P>0.16$ ). Within the Mediterranean basin, however, significant differentiation was observed (global exact test for unpooled and pooled data sets, $P<0.001$ ). This was mainly the result of a reversal in relative frequencies of $\mathrm{H} 12$ and $\mathrm{H} 13$ in samples from the Adriatic Sea compared to other Mediterranean samples (Table 3 ). $F_{\mathrm{ST}}$ values between the Adriatic
Sea and all other Mediterranean samples were very high (0.31-0.36) and highly significant (Table 5). Conversely, no differentiation was apparent among the Ligurian Sea, Tyrrhenian Sea and Gulf of Gabès samples. $F_{S T}$ estimates between three samples from the Black Sea ranged from 0.02 to 0.10 and did not significantly differ from zero. When pooled per year, $F_{\mathrm{ST}}$ amounted to 0.09 and was marginally significant, suggesting that low sample sizes may have been the reason for nonsignificant differentiation within this basin [Table 5; global exact test, $P$ (unpooled) $=0.14$ and $P$ (pooled $)=0.02$ ]

Analysis of molecular variance (AMOVA) indicated that a large proportion of the total mitochondrial variation resided among basins (69.81\%, Table 6). Within the NE Atlantic, a small and nonsignificant part of the variance was distributed among regions $(0.16 \%)$ or among years $(0.19 \%)$. For both the NE Atlantic and Black Sea, the proportion of the variance distributed among pooled samples was higher than for unpooled samples, but not significant after Bonferroni corrections. Within the Mediterranean basin, however, large portions of the total mitochondrial variation were distributed among regions (20.0\%) or among samples (15.47 and $17.10 \%)$, and all associated $\Phi_{\mathrm{ST}}$ values were highly significant (Table 6).

Microsatellite DNA. All four loci contributed to betweensample differentiation, although not equally (global single locus $F_{\mathrm{ST}}$ values were 0.006 for Sset- $1,0.015$ for Sset-2, 0.012 for Sset-3 and 0.011 for Sset- 4 using data uncorrected for null alleles). Significant heterogeneity between sample pairs was most often detected between samples from different basins: $90.6 \%$ and $100 \%$ of all significant comparisons using uncorrected and data corrected for null alleles, respectively. Since levels of differentiation can be substantially overestimated when null alleles are present (O'Reilly et al. 2004), we present results for the corrected data set unless stated otherwise. Multilocus estimates of $F_{\mathrm{ST}}$ between basins were 0.012 (NE AtlanticMediterranean), 0.016 (NE Atlantic-Black Sea) and 0.020 (Mediterranean-Black Sea). When pairwise $F_{\mathrm{ST}}$ values were plotted using MDS between all unpooled and pooled samples (Fig. 4A and B, respectively), it is clear that pooling of samples increased the signal of differentiation between basins as opposed to the differentiation within basins. By pooling samples, and thus increasing sample sizes, the statistical power to reject homogeneity between basins also increased.

Pairwise multilocus $F_{\mathrm{ST}}$ between pooled samples and the probability of genetic heterogeneity are given in Table 5. Within the NE Atlantic, $F_{\mathrm{ST}}$ estimates were very low, with a maximum of 0.026 between 99skag1 A and 01sb1B for the unpooled data set, and 0.012 between ATL01 and GB01 for the pooled data set. None of the pairwise exact tests within this basin were significant after Bonferroni corrections. 
Table 5 Estimates of genetic differentiation $\left(F_{\mathrm{ST}}\right)$ between samples of Sagitta setosa (sample codes as in Table 1). Above diagonal: $F_{\mathrm{ST}}$ incorporating genetic distances between haplotypes from RFLP analysis of the mitochondrial COII region. Below diagonal: multilocus $F_{\mathrm{ST}}$ (Weir \& Cockerham 1984) based on variation at four microsatellite loci (loci Sset-3 and Sset-4 were corrected for null alleles; see text). Significant deviations from genetic homogeneity (exact test: below diagonal; permutation test: above diagonal) are shown in italics when $P<0.01$, and in bold type when remaining significant after sequential Bonferroni correction for multiple tests

\begin{tabular}{|c|c|c|c|c|c|c|c|c|c|c|c|c|c|c|c|c|c|c|}
\hline \multirow[b]{2}{*}{$n$} & & \multicolumn{10}{|c|}{ NE Atlantic } & \multicolumn{5}{|c|}{ Mediterranean Sea } & \multicolumn{2}{|c|}{ Black Sea } \\
\hline & & SKAG99 & GB99 & SB99 & CELTO0 & ATL00 & SKAG01 & ATL01 & GB01 & SB01 & CHAN01 & LIG99 & LIG01 & TYR02 & GAB02 & ADR00 & BLACK00 & BLACK02 \\
\hline 162 & SKAG99 & & -0.0018 & 0.0046 & -0.0096 & 0.0171 & -0.0033 & 0.0028 & 0.0036 & 0.0015 & 0.0003 & 0.6476 & 0.6674 & 0.6970 & 0.6988 & 0.7829 & 0.7185 & 0.6646 \\
\hline 177 & GB99 & 0.0006 & & 0.0072 & -0.0114 & 0.0120 & -0.0031 & 0.0121 & 0.0038 & 0.0069 & 0.0001 & 0.6431 & 0.6623 & 0.6910 & 0.6930 & 0.7795 & 0.7111 & 0.6565 \\
\hline 155 & SB99 & -0.0009 & -0.0015 & & 0.0066 & 0.0251 & 0.0052 & 0.0018 & 0.0005 & 0.0068 & 0.0007 & 0.6722 & 0.6940 & 0.7288 & 0.7282 & 0.7999 & 0.7688 & 0.7170 \\
\hline 48 & CELT00 & -0.0010 & -0.0012 & -0.0014 & & 0.0134 & -0.0082 & 0.0108 & 0.0021 & 0.0014 & 0.0001 & 0.5952 & 0.6210 & 0.6671 & 0.6646 & 0.7507 & 0.7248 & 0.6164 \\
\hline 56 & ATL00 & -0.0030 & -0.0022 & -0.0019 & -0.0020 & & 0.0121 & 0.0150 & 0.0219 & 0.0289 & 0.0043 & 0.5541 & 0.5801 & 0.6225 & 0.6214 & 0.7247 & 0.6753 & 0.5767 \\
\hline 141 & SKAG01 & -0.0011 & -0.0018 & -0.0025 & -0.0025 & -0.0022 & & 0.0034 & -0.0016 & -0.0008 & -0.0005 & 0.6538 & 0.6761 & 0.7123 & 0.7128 & 0.7937 & 0.7476 & 0.6876 \\
\hline 50 & ATL01 & 0.0090 & 0.0047 & 0.0043 & 0.0058 & 0.0043 & 0.0043 & & 0.0052 & -0.0039 & 0.0112 & 0.5983 & 0.6260 & 0.6740 & 0.6707 & 0.7562 & 0.7475 & 0.6483 \\
\hline 230 & GB01 & 0.0007 & 0.0021 & 0.0008 & 0.0000 & -0.0004 & 0.0006 & 0.0119 & & 0.0019 & -0.0009 & 0.7061 & 0.7261 & 0.7572 & 0.7579 & 0.8272 & 0.7886 & 0.7461 \\
\hline 199 & SB01 & -0.0004 & 0.0011 & -0.0013 & -0.0015 & -0.0009 & -0.0008 & 0.0094 & -0.0002 & & 0.0154 & 0.6928 & 0.7140 & 0.7475 & 0.7484 & 0.8218 & 0.7798 & 0.7334 \\
\hline 50 & CHAN01 & -0.0009 & 0.0006 & -0.0001 & -0.0034 & -0.0025 & -0.0016 & 0.0037 & 0.0001 & -0.0005 & & 0.6074 & 0.6339 & 0.6807 & 0.6767 & 0.7552 & 0.7524 & 0.6501 \\
\hline 96 & LIG99 & 0.0048 & 0.0137 & 0.0085 & 0.0062 & 0.0058 & 0.0086 & 0.0250 & 0.0056 & 0.0059 & 0.0081 & & -0.0106 & -0.0063 & 0.0031 & 0.3450 & 0.0685 & 0.0741 \\
\hline 88 & LIG01 & 0.0111 & 0.0223 & 0.0180 & 0.0135 & 0.0115 & 0.0178 & 0.0372 & 0.0139 & 0.0128 & 0.0169 & -0.0004 & & -0.0076 & 0.0003 & 0.3494 & 0.0838 & 0.0852 \\
\hline 67 & TYR02 & 0.0073 & 0.0131 & 0.0086 & 0.0066 & 0.0047 & 0.0106 & 0.0272 & 0.0074 & 0.0070 & 0.0114 & -0.0015 & -0.0006 & & -0.0083 & 0.3610 & 0.1100 & 0.1368 \\
\hline 69 & GAB02 & 0.0077 & 0.0138 & 0.0093 & 0.0094 & 0.0044 & 0.0110 & 0.0273 & 0.0116 & 0.0092 & 0.0108 & 0.0005 & 0.0037 & -0.0002 & & 0.3069 & 0.1574 & 0.1655 \\
\hline 80 & ADR00 & 0.0089 & 0.0177 & 0.0139 & 0.0103 & 0.0093 & 0.0139 & 0.0311 & 0.0087 & 0.0089 & 0.0125 & -0.0018 & -0.0022 & -0.0032 & 0.0041 & & 0.5569 & 0.5160 \\
\hline 30 & BLACK00 & 0.0146 & 0.0119 & 0.0155 & 0.0153 & 0.0069 & 0.0149 & 0.0291 & 0.0141 & 0.0191 & 0.0152 & 0.0223 & 0.0249 & 0.0150 & 0.0214 & 0.0251 & & 0.0880 \\
\hline 26 & BLACK02 & 0.0141 & 0.0110 & 0.0154 & 0.0105 & 0.0070 & 0.0122 & 0.0287 & 0.0106 & 0.0165 & 0.0131 & 0.0154 & 0.0181 & 0.0107 & 0.0141 & 0.0172 & -0.0056 & \\
\hline
\end{tabular}


Table 6 Hierarchical analyses of mitochondrial DNA (mtDNA) and nuclear DNA (nDNA) molecular variance (AMOvA) amongst three European basins (A), within the Northeast Atlantic (B), within the Mediterranean Sea (C) and within the Black Sea (D) showing the proportion of total variance distributed between various groups of samples. For within basin comparisons, the results of two single-level AMOVAs (one group of samples) are given first for separate and pooled samples, respectively, and as the among-samples component only $\left(\Phi_{\mathrm{ST}}\right)$. Associated with each hierarchical level are: degrees of freedom (d.f.), percentage of total variance explained (\%), $\Phi$-statistics incorporating Nei \& Tajima's (1981) distance among RFLP haplotypes for mtDNA and using allele frequencies (multilocus, corrected for null alleles) for nDNA. Estimates of statistical significance are given as probabilities of having, by chance alone, a more extreme variance component and $\Phi$-statistic than the observed value (determined by 10000 permutations): NS, not significant, ${ }^{*} P<0.05,{ }^{* *} P<0.01$, $* * *<<0.001$; values in bold type remain significant after sequential Bonferroni corrections

\begin{tabular}{|c|c|c|c|c|c|c|c|c|}
\hline \multirow[b]{2}{*}{ Source of variation } & \multicolumn{4}{|c|}{ mtDNA } & \multicolumn{4}{|c|}{ nDNA } \\
\hline & d.f. & $\%$ & $\Phi$-statistics & & d.f. & $\%$ & $\Phi$-statistics & \\
\hline \multicolumn{9}{|l|}{ (A) Three basins } \\
\hline Among basins (39 samples, 3 groups) & 2 & 69.81 & $\Phi_{\mathrm{CT}}=0.6981$ & $* * *$ & 2 & 0.93 & $\Phi_{\mathrm{CT}}=0.0093$ & $* * *$ \\
\hline Among samples within basins & 36 & 2.03 & $\Phi_{\mathrm{SC}}=0.0673$ & $* * *$ & 36 & 0.04 & $\Phi_{\mathrm{SC}}=0.0004$ & NS \\
\hline Within samples & 1685 & 28.16 & $\Phi_{\mathrm{ST}}=0.7184$ & $* * *$ & 3409 & 99.03 & $\Phi_{\mathrm{ST}}=0.0097$ & $* * *$ \\
\hline \multicolumn{9}{|l|}{ (B) Within NE Atlantic } \\
\hline Among samples (27 samples) & 26 & 0.22 & $\Phi_{\mathrm{ST}}=0.0022$ & NS & 26 & 0.04 & $\Phi_{\mathrm{ST}}=0.0004$ & NS \\
\hline Among samples (10 pooled samples) & 9 & 0.36 & $\Phi_{\mathrm{ST}}=0.0036$ & $*$ & 9 & -0.05 & $\Phi_{\mathrm{ST}}=-0.0006$ & NS \\
\hline Among regions (6 groups) & 5 & 0.16 & $\Phi_{\mathrm{CT}}=0.0016$ & NS & 5 & -0.04 & $\Phi_{\mathrm{CT}}=-0.0004$ & NS \\
\hline Among samples within regions & 21 & 0.09 & $\Phi_{\mathrm{SC}}=0.0009$ & NS & 21 & 0.07 & $\Phi_{\mathrm{SC}}=0.0007$ & NS \\
\hline Within samples & 1241 & 99.75 & $\Phi_{\mathrm{ST}}=0.0025$ & NS & 2509 & 99.96 & $\Phi_{\mathrm{ST}}=0.0004$ & NS \\
\hline Among years (3 groups) & 2 & 0.19 & $\Phi_{\mathrm{CT}}=0.0019$ & NS & 2 & -0.02 & $\Phi_{\mathrm{CT}}=-0.0002$ & NS \\
\hline Among samples within years & 24 & 0.11 & $\Phi_{\mathrm{SC}}=0.0011$ & NS & 24 & 0.06 & $\Phi_{\mathrm{SC}}=0.0006$ & NS \\
\hline Within samples & 1241 & 99.71 & $\Phi_{\mathrm{ST}}=0.0029$ & NS & 2509 & 99.97 & $\Phi_{\mathrm{ST}}=0.0003$ & NS \\
\hline \multicolumn{9}{|l|}{ (C) Within Mediterranean Sea } \\
\hline Among samples (9 samples) & 8 & 15.47 & $\Phi_{\mathrm{ST}}=0.1547$ & $* * *$ & 8 & -0.06 & $\Phi_{\mathrm{ST}}=-0.0006$ & NS \\
\hline Among samples (5 pooled samples) & 4 & 17.10 & $\Phi_{\mathrm{ST}}=\mathbf{0 . 1 7 1 0}$ & $* * *$ & 4 & 0.58 & $\Phi_{\mathrm{ST}}=\mathbf{0 . 0 0 5 8}$ & $* *$ \\
\hline Among regions (4 groups) & 3 & 20.00 & $\Phi_{\mathrm{CT}}=0.2000$ & $*$ & 3 & -0.25 & $\Phi_{\mathrm{CT}}=-0.0025$ & NS \\
\hline Among samples within regions & 5 & -0.96 & $\Phi_{\mathrm{SC}}=-0.0120$ & NS & 5 & 0.14 & $\Phi_{\mathrm{SC}}=0.0014$ & NS \\
\hline Within samples & 391 & 80.96 & $\Phi_{\mathrm{ST}}=0.1904$ & $* * *$ & 791 & 100.11 & $\Phi_{\mathrm{ST}}=-0.0012$ & NS \\
\hline \multicolumn{9}{|l|}{ (D) Within Black Sea } \\
\hline Among samples (3 samples) & 2 & 5.39 & $\Phi_{\mathrm{ST}}=0.0539$ & * & 2 & 0.39 & $\Phi_{\mathrm{ST}}=0.0039$ & NS \\
\hline Among samples (2 pooled samples) & 1 & 8.80 & $\Phi_{\mathrm{ST}}=0.0880$ & $* *$ & 1 & -0.26 & $\Phi_{\mathrm{ST}}=-0.0026$ & NS \\
\hline
\end{tabular}

Global exact tests over all NE Atlantic samples were significant when samples were unpooled $(P=0.001)$ but insignificant when samples were pooled $(P=0.089)$ although $F_{\mathrm{ST}}$ estimates were negligible in both cases $(-0.0006$ and 0.0003 , respectively). Similarly, the MDS plots show no association of samples according to different regions or years within the NE Atlantic, although 'ATL01' appears separate from other samples (Fig. 4). Possible reasons for this are the relatively low sample size of 'ATL01' $(n=50)$ because it was not pooled with other samples, and the fact that it was not corrected for null alleles at locus Sset-4.

Within the Mediterranean Sea, global exact tests were significant for both unpooled and pooled data sets ( $P=0.0001$ and 0.0021 , respectively). However, none of the pairwise tests indicated significant genic differentiation (Table 5). Pairwise $F_{\mathrm{ST}}$ values were negative for all comparisons except between the Gulf of Gabès (GAB02) and other Mediterranean samples, which were very low $(0.0005-$ 0.0041) and only marginally significant (Table 5). Contrary to results from mtDNA data, the Adriatic Sea was not significantly differentiated from other Mediterranean samples. Within the Black Sea, no evidence of sample differentiation was found (global exact test, $P=0.15$ and 0.60 for unpooled and pooled data, respectively).

Consistent with these results, AMOvas based on allelic frequencies indicated that a tiny, but highly significant, fraction of the total nuclear variance was distributed among the three basins $(0.93 \%)$ and that the vast majority was present within samples (99.03\%, Table 6). For both the NE Atlantic and Black Sea, AMOvAs did not detect any significant portion of the variance distributed among samples, regions or years within these basins. Within the Mediterranean basin, however, a small but significant portion was distributed among pooled samples $(0.58 \%)$, which resulted from inclusion of the Gulf of Gabès sample only.

\section{Discussion}

Combined analysis of mitochondrial and nuclear data for 1724 Sagitta setosa individuals from three European 
3332 K. T. C. A. PEIJNENBURG ET AL.

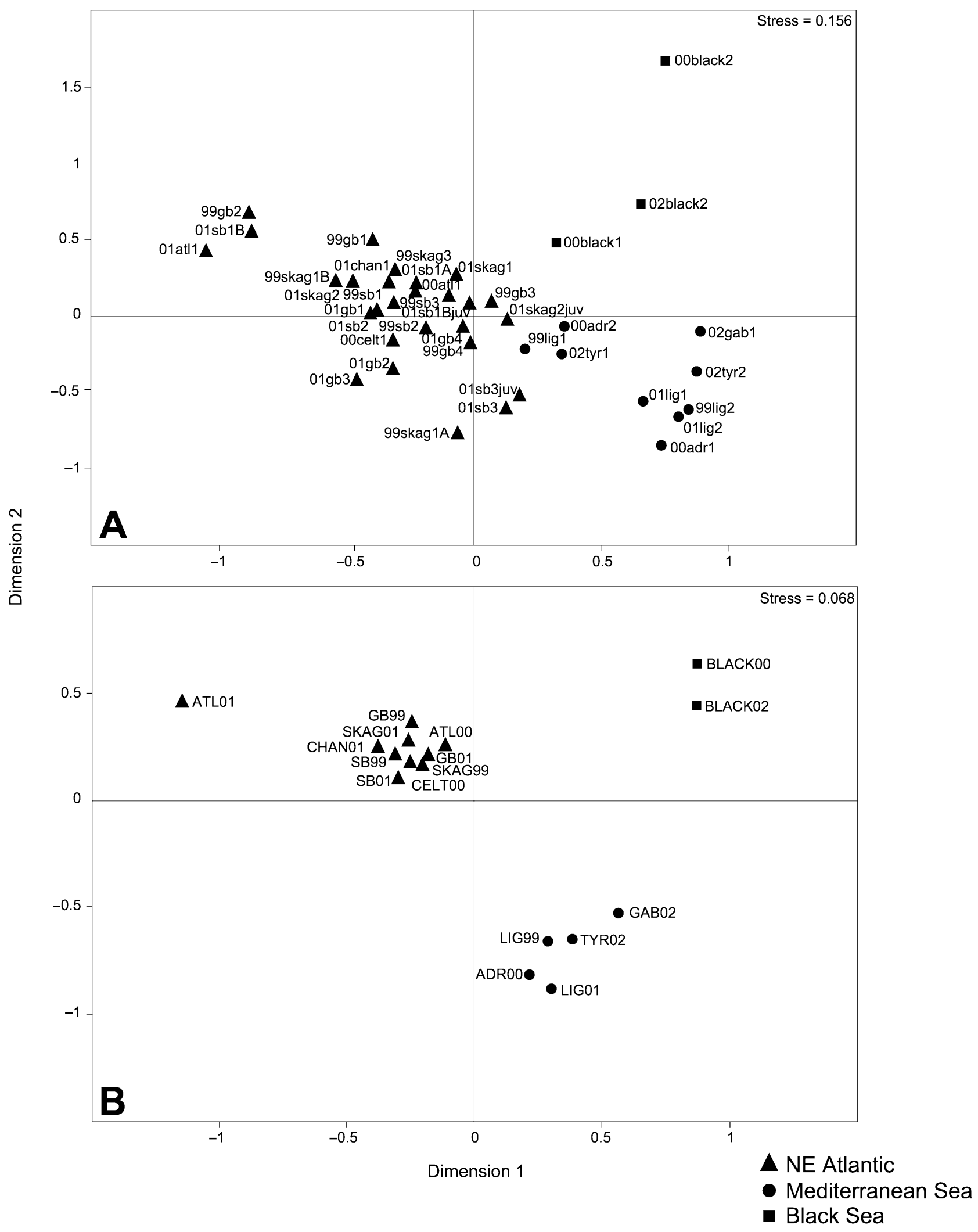

Fig. 4 Multidimensional scaling plots of pairwise multilocus $F_{\mathrm{ST}}$ (Weir \& Cockerham 1984) based on four microsatellites (of which Sset-3 and Sset- 4 were corrected for null alleles, see text) among 39 samples (A) and 17 pooled samples (B) of Sagitta setosa from the Northeast Atlantic, Mediterranean Sea and Black Sea (see legend; see Table 1 for sample codes). 
seas revealed qualitatively congruent patterns of differentiation on large (between-basin) and smaller (within-basin) spatial scales. Both data sets indicated significant differentiation between populations from the NE Atlantic, Mediterranean and Black Sea. Congruent patterns were also observed within basins with no evidence of spatial or temporal structuring in the NE Atlantic, evidence of differentiation in the Mediterranean Sea (although patterns of substructuring were different as indicated by the two marker sets), and inconclusive results about structuring in the Black Sea. Quantitatively, however, the levels of differentiation were different, with far less pronounced structure detected by nuclear than mitochondrial markers. Alongside such information on $S$. setosa population structure, our study uncovered the presence of highly divergent mitochondrial lineages that were discordant with morphology, geography and nuclear DNA.

\section{Between-basin genetic structure}

Estimates of divergence based on COII PCR-RFLPs were high, with similar $F_{\mathrm{ST}}$ estimates between NE Atlantic and Mediterranean, and NE Atlantic and Black Sea populations, and the lowest estimate between Mediterranean and Black Sea populations. These results are congruent with sequence data from the same fragment, although estimates of net nucleotide divergence from RFLPs were lower compared to sequence data (a factor of 1.5-3.3; Peijnenburg et al. 2004). This may be explained by the fact that sequence data were corrected for saturation whereas RFLP data were not. Moreover, restriction enzymes sampled only a subset of the variation present within the COII fragment. This also explains why some RFLP haplotypes (e.g. H1 and H12-H15) were shared across basins while sequences of representatives of these haplotypes were grouped into monophyletic geographic clades (Fig. 3). Taken together, RFLP analysis provided an efficient method for screening large numbers of individuals for mtDNA variation and corroborate earlier conclusions that Atlantic, Mediterranean and Black Sea populations of $S$. setosa are probably disjunct. Furthermore, the pattern of population divergences is consistent with deep splits between Atlantic and Mediterranean populations and colonization of the Black Sea from the Mediterranean as proposed by Peijnenburg et al. (2004). Similar patterns were observed for mussels (Ladoukakis et al. 2002) and copepods (Papadopoulos et al. 2005).

Microsatellite data also indicated significant structuring among basins. However, $F_{\mathrm{ST}}$ estimates were much lower than RFLP-based estimates (a factor of 7.6-62.0). Contrary to mtDNA data, the lowest levels of differentiation were between NE Atlantic and Mediterranean, and NE Atlantic and Black Sea populations, and the highest estimate between Mediterranean and Black Sea populations. This discrepancy is most likely the result of higher levels of homoplasy for microsatellites than mtDNA, although other explanations are also possible (see below). Microsatellite data, however, provide independent support that phylogeographic breaks (sensu category I of Avise et al. 1987) exist between S. setosa populations from the three European seas.

\section{Within-basin genetic structure}

Genetic homogeneity among samples from different regions and years suggests that $S$. setosa constitutes a single interbreeding population within the NE Atlantic. This result is not surprising for a holoplanktonic species, considering that there is a single anticlockwise circulation in this region, and that the relevant time scales for mixing of waters from the entire shelf is of the order of years (Prandle 1984). Similar results were obtained for NE Atlantic populations of flatfish (Borsa et al. 1997; Hoarau et al. 2002, 2004) and squid (Shaw et al. 1999). Two other studies, however, examining mitochondrial variation in a goby (Gysels et al. 2004) and crab (Roman \& Palumbi 2004), reported a barrier separating North Sea populations from more southern populations in the English Channel and Celtic Sea. An alternative explanation for the observed homogeneity of $S$. setosa is that populations have not yet reached an equilibrium between gene flow and genetic drift, so that significant structuring is not revealed by our genetic markers. Even though we cannot exclude this explanation, it is unlikely because of our extensive sampling of mitochondrial and nuclear diversity and the fact that we found significant structuring within the Mediterranean basin using the same markers.

Another pattern contained in our NE Atlantic data set was that of genetic patchiness, i.e. samples separated by $0-100 \mathrm{~km}$ were sometimes as genetically different as samples separated by 100-1000 km (Fig. 4). Some pairwise $F_{\mathrm{ST}}$ estimates were indeed quite high for a planktonic organism (max. 0.037 for mtDNA and 0.026 for microsatellites) and some indicated marginally significant differentiation. However, such patterns were not consistent across markers nor across years, and are therefore not interpreted in terms of population structuring. One explanation for these 'chaotic' patterns may be that insufficient sample sizes resulted in overestimates of genetic differentiation, especially since levels of variability of our markers were very high and levels of differentiation within this basin were very low (Ruzzante 1998; Waples 1998; Kalinowski 2005). Support for this comes from the fact that our estimates of $F_{\mathrm{ST}}$ and significance of exact tests were generally reduced when NE Atlantic samples were pooled per region and year to increase sample size.

Significant heterogeneity within the Mediterranean basin was detected by both mtDNA and microsatellite markers, and for both unpooled and pooled data sets. This 
result is consistent with our hypothesis that higher levels of genetic structuring were expected for the Mediterranean than the NE Atlantic because of the division into several subbasins and the presence of fragmented neritic habitats in the Mediterranean basin. Also consistent with this hypothesis is the higher level of mitochondrial diversity in Mediterranean than NE Atlantic samples, though this pattern was not apparent for microsatellites. Frequency distributions of RFLP haplotypes were also least skewed, and genealogical structure was deepest for Mediterranean samples. These results suggest that Mediterranean S. setosa populations are genetically structured because gene flow between sub-basins is limited, or alternatively, that populations are presently connected by gene flow but diverged in the past (e.g. because of survival in different Pleistocene refugia). Mediterranean populations may also have had an effective population size larger than the NE Atlantic population, possibly resulting from less severe bottlenecks and/or selective sweeps. A combination of these possibilities is also conceivable.

Mitochondrial DNA data provided strong evidence that the Adriatic population of $S$. setosa is genetically differentiated from Ligurian, Tyrrhenian and Gulf of Gabès populations. Microsatellites, however, did not detect any differentiation between Adriatic and other Mediterranean samples, but instead suggested slight and marginally significant differentiation of the Gulf of Gabès sample. It should be stressed, though, that this differentiation was minimal, and based on allelic frequency differences at a single microsatellite locus (Sset-4) and a single sample from the Gulf of Gabès, and should therefore be interpreted cautiously. Differentiation between Adriatic and western Mediterranean populations is consistent with earlier results for $S$. setosa (Peijnenburg et al. 2004), several marine fish (Borsa et al. 1997; Bahri-Sfar et al. 2000; Stefanni \& Thorley 2003) and a bivalve (Mariani et al. 2002).

There are several, mutually nonexclusive explanations for the discrepancy between mitochondrial and nuclear data in detecting the differentiation of the Adriatic Sea population, and for the higher estimates of population divergence detected by mtDNA in general. First, mitochondrial markers are generally more sensitive in detecting differentiation because of a lower effective population size than nuclear markers (e.g. Buonaccorsi et al. 2001; Shaw et al. 2004). Second, sex-biased dispersal or survival is often cited to explain discrepancies between mtDNA and nDNA, but this seems implausible for a hermaphroditic species (but see Diaz-Almela et al. 2004 for a possible example). Third, selection may have differential effects on different genetic markers. Most examples, however, involve selection acting on certain allozyme loci (e.g. Lemaire et al. 2000; De Innocentiis et al. 2001; Arnaud-Haond et al. 2003). A dominant role for purifying selection in the evolution of mtDNA has also been suggested (Ballard \& Whitlock
2004). We believe that selection on mtDNA may accelerate the coalescence of lineages, and thus increase levels of differentiation observed between populations. Furthermore, the effect of (slight) selection pressures may be more important in large (pelagic) populations of marine organisms because the effect of drift is diminished. In particular, we reported indirect evidence of selection acting on the mitochondrial COII region in chaetognaths (Peijnenburg et al. 2004, 2005). Fourth, various technical problems may have reduced the signal of differentiation detected by our microsatellite markers. Microsatellites probably suffered from higher levels of homoplasy than mtDNA because of high mutation rates (especially when combined with allelic size constraints) and larger effective population size, inflating the apparent similarity between populations (Nauta \& Weissing 1996; Balloux et al. 2000; Estoup et al. 2002). Also, two out of four microsatellite loci were hypervariable (Sset-3 and Sset-4 had 54 and 89 alleles, respectively) and suffered from a high incidence of null alleles. Our results indicated that correcting for null alleles reduced the signal as well as the power to detect differentiation. Similarly, O'Reilly et al. (2004) comparing 14 microsatellite loci with varying levels of polymorphism in a marine fish, showed that estimates of differentiation and the probability to detect genetic differences among populations both diminished when locus heterozygosities increased and data were corrected for null alleles. Finally, a potential problem with the microsatellite data set is related to sample size. Even though sample sizes of at least 50 are generally considered sufficient to produce precise estimates of $F_{\mathrm{ST}}$ with highly variable loci (Ruzzante 1998), this may not be the case when $F_{\mathrm{ST}}$ values are low (Kalinowski 2005). We found that the signal of differentiation between basins and within the Mediterranean basin increased when samples were pooled (Fig. 4; Table 6), suggesting that (much) larger samples may be necessary to detect differentiation of $S$. setosa populations in the Mediterranean Sea using highly variable nuclear markers. Summarizing, our data are inconclusive about whether Adriatic populations are presently connected by gene flow with other Mediterranean populations; however, mitochondrial data indicate that they have diverged in the past. Likewise, we cannot conclude whether populations within the Black Sea are genetically structured because sampling intensity was probably too low to detect subtle levels of differentiation with our highly variable markers.

\section{Discordant mitochondrial lineages}

Using RFLPs to screen for polymorphism within the COII fragment and subsequent sequencing of new haplotypes, we uncovered the presence of three groups of divergent mitochondrial lineages that were discordant with geography (Fig. 3). These groups were denoted Clade A, Sagitta sp. 
I and Sagitta sp. II and were detected in samples that were morphologically identified as S. setosa. Interestingly, all samples with divergent mtDNA showed common nuclear DNA patterns. Furthermore, mitochondrial amplification failures of Black Sea samples (39\%) may represent additional, highly divergent mitochondrial lineages where point mutations have occurred in the primer regions of the COII fragment, but not at any of the four nuclear loci.

Clade A grouped with the majority of S. setosa haplotypes and appeared intermediate between NE Atlantic and Mediterranean/Black Sea clades (Fig. 3). Nine individuals were found to belong to Clade A, seven from widespread locations in the NE Atlantic and two from the Black Sea. These results indicate that Clade $\mathrm{A}$ individuals shared a more recent common ancestor than with the majority of S. setosa individuals (see also Peijnenburg et al. 2004). It may be that Clade A represents remnants of ancestral lineages (before the splitting of major phylogeographic groups) that have not been lost from present populations by the process of lineage sorting (or selection). The fact that Atlantic and Black Sea haplotypes within this clade are separated into two subclades suggests that they have diverged (average maximum-likelihood sequence divergence is $1.60 \%$ and net divergence is $0.62 \%$ ), and are thus unlikely to represent recent dispersal between the NE Atlantic and Black Sea basins (e.g. by ballast water).

Sagitta sp. I and Sagitta sp. II were highly differentiated from $S$. setosa with average corrected sequence divergences of $14.49 \%$ and $25.92 \%$, respectively, as opposed to average within-clade divergences of $0.20-4.42 \%$. This pattern corresponds to phylogeographic category II (sensu Avise et al. 1987) in which highly distinct mitochondrial lineages lack geographic localization. These lineages may originate from either unidentified sympatric sibling species or from previously isolated populations that presently interbreed. Such extremely high levels of divergence for a mitochondrial protein-coding gene are generally considered indicative of at least species-level status. For example, divergences of $\sim 5-25 \%$ at mitochondrial protein-coding genes in several marine species were considered as evidence of cryptic species (Lee 2000; Rocha-Olivares et al. 2001; Lee \& Frost 2002; Goetze 2003; Lee \& Foighil 2004). However, these studies also reported congruent patterns of divergence at nuclear loci confirming that divergent lineages were probably reproductively isolated. We, however, did not find concordant patterns at nuclear loci. Even sequence data of microsatellite alleles did not show any fixed differences between any of the deep mitochondrial clades at the nucleotide level (K. T. C. A. Peijnenburg et al., unpublished results). This suggests that highly divergent mitochondrial lineages may be present in interbreeding populations of S. setosa. In very large populations it would theoretically be possible that anciently separated lineages are retained by chance whereas intermediate haplotypes have been lost by gradual lineage sorting, although examples are lacking (Avise 2000). Hybridization and introgression of mtDNA across chaetognath species may be another possibility. To test these hypotheses, we need more data of other nuclear markers and a molecular species phylogeny of chaetognaths.

\section{Acknowledgements}

We would like to thank the many people who helped us to obtain samples from various areas: M. Tuerkay, J. Fives, G. Duineveld, C. ten Hallers-Tjabes, H. van Aken, H. Thomas, all crew of Research Vessel 'Pelagia', S. Dallot, E. Ghirardelli, E. Vinzi, N. Bajkoviç, M. Flint, V. Velikova, V. Mihneva, H. Harrath, M.-G. Mazzocchi, S. Piontkovsky, A. Pierrot-Bults, H. Pierrot, R. ter Hofstede, J.-H. Schotveld and E. van Haastrecht. We also especially thank M. Flint (P. P. Shirshov Institute of Oceanology, Moscow, Russia) and S. Piontkovsky (Institute of Biology of the Southern Seas, Sevastopol, Ukraine) for sending us the Black Sea samples from 2000 and 2002, respectively. We also acknowledge B. Voetdijk, W. van Ginkel, P. Kuperus and S. van Heiningen for laboratory assistance, Westburg for technical advice about LI-COR systems, J. van Arkel for producing Figs 1, 2 and 3, M. van Ballegooijen, G. Hoarau, J. Olsen, W. Stam, M. Canino, C. van Oosterhout and many people at the Institute for Biodiversity and Ecosystem Dynamics of the University of Amsterdam for advice and discussion. Comments on the manuscript from two anonymous referees, P. Luttikhuizen and S. Mariani were also greatly appreciated. This work was part of the priority program 'Sustainable use and conservation of marine living resources' and was funded by the Netherlands Organization for Scientific Research (NWO project 885.100.02).

\section{References}

Arnaud-Haond S, Bonhomme F, Blanc F (2003) Large discrepancies in differentiation of allozymes, nuclear and mitochondrial DNA loci in recently founded Pacific populations of the pearl oyster Pinctada margaritifera. Journal of Evolutionary Biology, 16, 388-398.

Avise JC (2000) Phylogeography: The History and Formation of Species. Harvard University Press, Cambridge, Massachusetts.

Avise JC, Arnold J, Ball RM et al. (1987) Intraspecific phylogeography: the mitochondrial DNA bridge between population genetics and systematics. Annual Reviews in Ecology and Systematics, 18, 489-522.

Bahri-Sfar L, Lemaire C, Ben Hassine OK, Bonhomme F (2000) Fragmentation of sea bass populations in the western and eastern Mediterranean as revealed by microsatellite polymorphism. Proceedings of the Royal Society of London Series B-Biological Sciences, 267, 929-935.

Ballard JWO, Whitlock MC (2004) The incomplete natural history of mitochondria. Molecular Ecology, 13, 729-744.

Balloux F, Brünner H, Lugon-Moulin N, Hausser J, Goudet J (2000) Microsatellites can be misleading: an empirical and simulation study. Evolution, 54, 1414-1422.

Boneh L, Kuperus P, van Tienderen PH (2003) Microsatellites in the bromeliads Tillandsia fasciculata and Guzmania monostachya. Molecular Ecology Notes, 3, 302-303. 
Borsa P, Blanquer A, Berrebi P (1997) Genetic structure of the flounders Platichthys flesus and P. stellatus at different geographic scales. Marine Biology, 129, 233-246.

Brookfield JFY (1996) A simple new method for estimating null allele frequency from heterozygote deficiency. Molecular Ecology, 5, 453-455.

Bucklin A, Kaartvedt S, Guarnieri M, Goswami U (2000) Population genetics of drifting (Calanus spp.) and resident (Acartia clausi) plankton in Norwegian fjords. Journal of Plankton Research, 22, 1237-1251.

Bucklin A, LaJeunesse TC, Curry E, Wallinga J, Garrison K (1996) Molecular diversity of the copepod, Nannocalanus minor: genetic evidence of species and population structure in the North Atlantic ocean. Journal of Marine Research, 54, 285-310.

Bucklin A, Smolenack SB, Bentley AM, Wiebe PH (1997) Gene flow patterns of the euphausiid, Meganyctiphanes norvegica, in the NW Atlantic based on mtDNA sequences for cytochrome $b$ and cytochrome oxidase I. Journal of Plankton Research, 19, 1763-1781.

Buonaccorsi VP, McDowell JR, Graves JE (2001) Reconciling patterns of inter-ocean molecular variance from four classes of molecular markers in blue marlin (Makaira nigricans). Molecular Ecology, 10, 1179-1196.

Darling KF, Wade CM, Stewart IA et al. (2000) Molecular evidence for genetic mixing of Arctic and Antarctic subpolar populations of planktonic foraminifers. Nature, 405, 43-47.

De Innocentiis S, Sola L, Cataudella S, Bentzen P (2001) Allozyme and microsatellite loci provide discordant estimates of population differentiation in the endangered dusky grouper (Epinephelus marginatus) within the Mediterranean Sea. Molecular Ecology, 10, 2163-2175.

De Vargas C, Norris R, Zaninetti L, Gibb SW, Pawlowski J (1999) Molecular evidence of cryptic speciation in planktonic foraminifers and their relation to oceanic provinces. Proceedings of the National Academy of Sciences USA, 96, 2864-2868.

De Vargas C, Bonzon M, Rees NW, Pawlowski J, Zaninetti L (2002) A molecular approach to biodiversity and biogeography in the planktonic foraminifer Globigerinella siphonifera (d'Orbigny). Marine Micropaleontology, 45, 101-116.

Diaz-Almela E, Boudry P, Launey S, Bonhomme F, Lapegue S (2004) Reduced female gene flow in the European flat oyster Ostrea edulis. Journal of Heredity, 95, 510-516.

Estoup A, Jarne P, Cornuet JM (2002) Homoplasy and mutation model at microsatellite loci and their consequences for population genetics analysis. Molecular Ecology, 11, 15911604.

Excoffier L, Smouse PE, Quattro JM (1992) Analysis of molecular variance inferred from metric distances among DNA haplotypes: application to human mitochondrial DNA restriction data. Genetics, 131, 497-491.

Furnestin M-L (1979) Aspects of the zoogeography of the Mediterranean plankton. In: Zoogeography and Diversity of Plankton (eds Van der Spoel S, Pierrot-Bults AC), pp. 191-253. Bunge Scientific Publishers, Utrecht.

Goetze E (2003) Cryptic speciation on the high seas; global phylogenetics of the copepod family Eucalanidae. Proceedings of the Royal Society of London Series B-Biological Sciences, 270, 23212331.

Goetze E (2005) Global population genetic structure and biogeography of the oceanic copepods Eucalanus hyalinus and S. Spinifer. Evolution, 59, 2378-2398.
Goudet J (2001) FSTAT: A program to estimate and test gene diversities and fixation indices, version 2.9.3. Available from: http:// www.unil.ch/izea/softwares/fstat.html.

Grosberg R, Cunningham CW (2001) Genetic structure in the sea; from populations to communities. In: Marine Community Ecology (eds Bertness CMD, Gaines S, Hay ME), pp. 61-84. Sinauer Associates, Sunderland, Massachusetts.

Gysels ES, Hellemans B, Pampoulie C, Volckaert FAM (2004) Phylogeography of the common goby, Pomatoschistus microps, with particular emphasis on the colonization of the Mediterranean and the North Sea. Molecular Ecology, 13, 403-417.

Hellberg ME, Burton RS, Neigel JE, Palumbi SR (2002) Genetic assessment of connectivity among marine populations. Bulletin of Marine Science, 70, 273-290.

Hoarau G, Rijnsdorp AD, Van der Veer HW, Stam WT, Olsen JL (2002) Population structure of plaice (Pleuronectes platessa L.) in northern Europe: microsatellites revealed large-scale spatial and temporal homogeneity. Molecular Ecology, 11, 11651176.

Hoarau G, Piquet AMT, van der Veer HW et al. (2004) Population structure of plaice (Pleuronectes platessa L.) in northern Europe: a comparison of resolving power between microsatellites and mitochondrial DNA data. Journal of Sea Research, 51, 183190.

John U, Fensome RA, Medlin LK (2003) The application of a molecular clock based on molecular sequences and the fossil record to explain biogeographic distributions within the Alexandrium tamarense 'species complex' (Dinophyceae). Molecular Biology and Evolution, 20, 1015-1027.

Kalinowski ST (2005) Do polymorphic loci require large sample sizes to estimate genetic distances? Heredity, 94, 33-36.

Kimura M, Crow JF (1964) The number of alleles that can be maintained in a finite population. Genetics, 49, 725-738.

Kimura M, Ohta T (1978) Stepwise mutation model and distribution of allelic frequencies in a finite population. Proceeding of the National Academy of Sciences of the USA, 75, 2868-2872.

Knowlton N (1993) Sibling species in the sea. Annual Review of Ecology and Systematics, 24, 189-216.

Knowlton N (2000) Molecular genetic analyses of species boundaries in the sea. Hydrobiologia, 420, 73-90.

Kruskal JB, Wish M (1978) Multidimensional Scaling. Sage Publications, California.

Ladoukakis ED, Saavedra C, Magoulas A, Zouros E (2002) Mitochondrial DNA variation in a species with two mitochondrial genomes: the case of Mytilus galloprovincialis from the Atlantic, the Mediterranean and the Black Sea. Molecular Ecology, 11, 755-769.

Lee CE (2000) Global phylogeography of a cryptic copepod species complex and reproductive isolation between genetically proximate 'populations'. Evolution, 54, 2014-2027.

Lee T, Foighil DO (2004) Hidden Floridian biodiversity: mitochondrial and nuclear gene trees reveal four cryptic species within the scorched mussel, Brachidontes exustus, species complex. Molecular Ecology, 13, 3527-3542.

Lee CE, Frost BW (2002) Morphological stasis in the Eurytemora affinis species complex (Copepoda: Temoridae). Hydrobiologia, 480, 111-128.

Lemaire C, Allegrucci G, Naciri M et al. (2000) Do discrepancies between microsatellite and allozyme variation reveal differential selection between sea and lagoon in the sea bass (Dicentrarchus labrax)? Molecular Ecology, 9, 457-467. 
Lunt DH, Hutchinson WF, Carvalho GR (1999) An efficient method for PCR-based isolation of microsatellite arrays (PIMA). Molecular Ecology, 8, 891-894.

Mariani S, Ketmaier V, de Matthaeis E (2002) Genetic structuring and gene flow in Cerastoderma glaucum (Bivalvia: Cardiidae): evidence from allozyme variation at different geographic scales. Marine Biology, 140, 687-697.

McElroy D, Moran P, Bermingham E, Konfield I (1992) REAP: an integrated environment for the manipulation and phylogenetic analysis of restriction data. Journal of Heredity, 83, 157-158.

Michalakis Y, Excoffier L (1996) A generic estimation of population subdivision using distances between alleles with special reference for microsatellite loci. Genetics, 142, 1061-1064.

Nauta MJ, Weissing FJ (1996) Constraints on allele size at microsatellite loci: implications for genetic differentiation. Genetics, 143, 1021-1032.

Nei M (1987) Molecular Evolutionary Genetics. Columbia University Press, New York.

Nei M, Miller JC (1990) A simple method for estimating average number of nucleotide substitutions within and between populations from restriction data. Genetics, 125, 873-879.

Nei M, Tajima F (1981) DNA polymorphism detectable by restriction endonucleases. Genetics, 97, 145-163.

Nei M, Tajima F (1983) Maximum likelihood estimation of the number of nucleotide substitutions from restriction sites data. Genetics, 105, 207-217.

Norris RD (2000) Pelagic species diversity, biogeography, and evolution. Paleobiology, 26, 236-258.

O'Reilly PT, Canino MF, Bailey KM, Bentzen P (2004) Inverse relationship between $F_{\mathrm{ST}}$ and microsatellite polymorphism in the marine fish, walleye pollock (Theragra chalcogramma): implications for resolving weak population structure. Molecular Ecology, 13, 1799-1814.

Otto L, Zimmerman JTF, Furnes GK et al. (1990) Review of the physical oceanography of the North Sea. Netherlands Journal of Sea Research, 26, 161-238.

Papadopoulos LP, Peijnenburg KTCA, Luttikhuizen PC (2005) Phylogeography of the calanoid copepods Calanus helgolandicus and C. euxinus suggests Pleistocene divergences between Atlantic, Mediterranean, and Black Sea populations. Marine Biology, 147, 1353-1365.

Pearre S (1991) Growth and reproduction. In: The Biology of Chaetognaths (eds Bone Q, Kapp H, Pierrot-Bults AC), pp. 61-75. Oxford University Press, Oxford.

Peijnenburg KTCA, Breeuwer JAJ, Pierrot-Bults AC, Menken SBJ (2004) Phylogeography of the planktonic chaetognath Sagitta setosa reveals isolation in European seas. Evolution, 58, 1472-1487.

Peijnenburg KTCA, van Haastrecht EK, Fauvelot C (2005) Presentday genetic composition suggests contrasting demographic histories of two dominant chaetognaths of the North-East Atlantic, Sagitta elegans and S. setosa. Marine Biology, 147, 12791289.

Pinardi N, Masetti E (2000) Variability of the large scale general circulation of the Mediterranean Sea from observations and modelling: a review. Palaeogeography Palaeoclimatology Palaeoecology, 158, 153-157.

Posada D, Crandall KA (1998) Modeltest: testing the model of DNA substitution. Bioinformatics, 14, 917-818.

Prandle D (1984) A modelling study of the mixing of 137Cs in the seas of the European continental shelf. Philosophical Transactions of the Royal Society of London Series A, 310, 407-436.
Raymond M, Rousset F (1995) GENEPOP (version 1.2): population genetics software for exact tests and ecumenicism. Journal of Heredity, 86, 248-249.

Rice WR (1989) Analysing tables of statistical tests. Evolution, 43, 223-225.

Rocha-Olivares A, Fleeger JW, Foltz DW (2001) Decoupling of molecular and morphological evolution in deep lineages of a meiobenthic harpacticoid copepod. Molecular Biology and Evolution, 18, 1088-1102.

Roman J, Palumbi SR (2004) A global invader at home: population structure of the green crab, Carcinus maenas, in Europe. Molecular Ecology, 13, 2891-2898.

Rozen S, Skaletsky HJ (1998) PRIMER 3, available at http://wwwgenome.wi.mit.edu/genome_software/other/primer3.html.

Ruzzante DE (1998) A comparison of several measures of genetic distance and population structure with microsatellite data: bias and sampling variance. Canadian Journal of Fisheries and Aquatic Sciences, 55, 1-14.

Sáez AG, Probert I, Geisen M et al. (2003) Pseudo-cryptic speciation in coccolithophores. Proceedings of the National Academy of Sciences USA, 100, 7163-7168.

Schneider S, Roessli D, Excoffier L (2000) ARLEQUIN, version 2.000: A software for population genetics data analysis genetics and biometry laboratory. Genetics and Biometry Laboratory, University of Geneva, Switzerland.

Schroth W, Jarms G, Streit B, Schierwater B (2002) Speciation and phylogeography in the cosmopolitan marine moon jelly, Aurelia sp. BMC Evolutionary Biology, 2, 1-10.

Shaw PW, Pierce GJ, Boyle PR (1999) Subtle population structuring within a highly vagile marine invertebrate, the veined squid Loligo forbesi, demonstrated with microsatellite DNA markers. Molecular Ecology, 8, 407-417.

Shaw PW, Arkhipkin AI, Al-Khairulla H (2004) Genetic structuring of Patagonian toothfish populations in the Southwest Atlantic Ocean: the effect of the Antarctic Polar Front and deepwater troughs as barriers to genetic exchange. Molecular Ecology, 13, 3293-3303.

Stefanni S, Thorley JL (2003) Mitochondrial DNA phylogeography reveals the existence of an Evolutionarily Significant Unit of the sand goby Pomatoschistus minutus in the Adriatic (Eastern Mediterranean). Molecular Phylogenetics and Evolution, 28, 601-609.

Stewart IA, Darling KF, Kroon D, Wade CM, Troelstra SR (2001) Genotypic variability in subarctic Atlantic planktic foraminifera. Marine Micropaleontology, 43, 143-153.

Swofford DL (1998) PAUP*, Phylogenetic Analysis Using Parsimony ( ${ }^{*}$ and Other Methods), version 4. Sinauer Associates, Sunderland.

Tamura K, Nei M (1993) Estimation of the number of nucleotide substitutions in the control region of mitochondrial DNA in humans and chimpanzees. Molecular Biology Evolution, 9, 678687.

Thuesen EV, Numachi K, Nemoto T (1993) Genetic variation in the planktonic chaetognaths Parasagitta elegans and Eukrohnia hamata. Marine Ecology Progress Series, 101, 243-251.

Van Oosterhout C, Hutchinson WF, Wills DPM, Shipley P (2004) MICRO-CHECKER: software for identifying and correcting genotyping errors in microsatellite data. Molecular Ecology Notes, 4, 535-538.

Waples RS (1998) Separating the wheat from the chaff: patterns of genetic differentiation in high gene flow species. Journal of Heredity, 89, 438-450. 
3338 K. T. C. A. PEIJNENBURG ET AL.

Weir BS, Cockerham CC (1984) Estimating F-statistics for the analysis of population structure. Evolution, 38, 1358-1370.

Zane L, Ostellari L, Maccatrozzo L et al. (1998) Molecular evidence for genetic subdivision of Antarctic krill (Euphausia superba Dana) populations. Proceedings of the Royal Society of London. Series B, Biological Sciences, 265, 2387-2391.

Zane L, Ostellari L, Maccatrozzo L et al. (2000) Genetic differentiation in a pelagic crustacean (Meganyctiphanes norvegica: Euhausiacea) from the North East Atlantic and the Mediterranean Sea. Marine Biology, 136, 191-199.

Zenkevitch L (1963) Biology of the Seas of the U.S.S.R. George Allen and Unwin, London.
This paper was part of the PhD work of Katja Peijnenburg, which aimed at unravelling spatial and temporal scales of marine plankton populations. Katja Peijnenburg worked in the Evolutionary Biology group at the University of Amsterdam and was supervised by Hans Breeuwer and Steph Menken. Cécile Fauvelot shares an interest in genetic population structures of marine organisms and contributed to this work during her postdoctoral position in Amsterdam. Katja Peijnenburg is currently working as a Postdoctoral Researcher at University College Dublin and pursues interests in stock structure and local adaptation of common whelk (Buccinum undatum). 